Article

\title{
Efficiency in Heating Operation of Low-Temperature Radiant Systems Working under Dynamic Conditions in Different Kinds of Buildings
}

\author{
Giulia Alessio®, Michele De Carli *, Angelo Zarrella and Antonino Di Bella® \\ Department of Industrial Engineering, University of Padua, 35131 Padova, Italy; \\ alessio_giulia@hotmail.it (G.A.); angelo.zarrella@unipd.it (A.Z.); antonino.dibella@unipd.it (A.D.B.) \\ * Correspondence: michele.decarli@unipd.it; Tel.: +39-049-827-6870
}

Received: 14 September 2018; Accepted: 5 November 2018; Published: 26 November 2018

\begin{abstract}
In recent years many types of radiant systems have been installed in buildings. Meanwhile, practitioners debate on which thermal inertia of radiant systems fit better and which control strategies should be better in buildings, depending on the insulation level and thermal inertia of the structures. In particular, in new and retrofitted buildings, where the envelope presents high levels of insulation, it is argued if it is better to have low or high inertia radiant systems for controlling the indoor operative temperature and avoid overheating, especially in mid-seasons when the outdoor temperature is mild and solar radiation is high. For this purpose a room with three types of insulation level has been analysed combining different types of structures (masonry, and light and timber walls) and three types of radiant systems (classic wet floor, dry floor, and ceiling). Two operation modes have been simulated: fixed supply temperature and variable temperature according to the outdoor temperature. The results looked at the embedded and control efficiency, the energy performance in case of coupling with a water to water heat pump and the long-term possible overheating analysis. The embedded and control efficiency in dynamic conditions has been evaluated and compared with different possible definitions, in particular with steady state conditions, former EN15316-2-2007, and current EN15316-2-2017. New values for the current standard are suggested based on the results of this work, since the former and existing values overestimate the seasonal losses of floor and radiant systems in heating conditions. The paper shows that working at variable temperature according to the outdoor air temperature leads to longer operation time. The temperature, on average, lowers, and coupling the radiant system with a water to water heat pump leads to lower consumptions in the case of variable supply temperature compared to fixed supply temperature over the season. The seasonal coefficient of performance of the whole system, i.e. the heat pump and auxiliary pumps, leads to overall lower energy consumption in the case of variable supply temperature. The simulations did not show any relevant problem of discomfort from December to February. Overtemperature effects in terms of operative temperatures over the dead band of the control systems are not especially due to the radiant system, but they also occur in any case with ideal convective systems. The paper demonstrates that in general the radiant floor systems perform better than radiant ceilings in heating conditions and there is no evidence that dry floor systems perform better than wet screed systems in all the types of buildings regardless of the level of insulation and thermal inertia.
\end{abstract}

Keywords: energy modelling; radiant systems in heating; building simulation 


\section{Introduction}

Radiant systems are being used for heating and cooling purposes for a long time [1,2]. Radiant ceilings are increasingly used, especially for commercial applications, but the most common type of radiant system is still the radiant floor.

The sizing of radiant systems has been debated in the past and standardized methods are today available [3]. Even though the systems are used and studied since several years, there are questions which are frequently asked by designers and practitioners which are still open and under discussion. The questions are related to the thermal inertia of the systems and which control strategies should be better in buildings during the heating period. In particular in new and retrofitted buildings, where the envelope presents high levels of insulation, it is argued if it is better to have low or high inertia radiant systems for controlling the indoor operative temperature and avoid overheating especially in mid seasons when outdoor temperature is mild and solar radiation is high. There are, hence, mainly two aspects to take simultaneously into account: the building envelope and the radiant systems.

Looking at building envelope, the thermal inertia of the building structure has been under debate for a long time. One of the first works looking at the different models to be used in the calculation of thermal behaviour of structures is the one of Bojic and Loveday [4], where several simplified methods were already criticized while dynamic simulations were predicted as most suitable methods. More recently thermal inertia of buildings structures has been debated, mainly in cooling conditions, e.g., $[5,6]$. Looking at results dealing with heating purposes, several papers have been published in the last years. Aste et al. [7] examined external wall systems with the same U-value but different dynamic properties in order to evaluate the associated achievable energy savings. They found that the difference in the heating demand with a low inertia wall compared to a high inertia one may reach about $10 \%$. A similar saving has been evaluated by Stazia et al. [8], who found a difference in heating conditions of about $15 \%$ among the different solutions of retrofit in both continuous and intermittent operation by combining both thermal insulation and thermal mass techniques in Mediterranean climates. These percentages seem to be the maximum difference which can be found in literature when dealing with heating demand in well-insulated buildings. As an example in [9] a parametric simulation study has been performed based on different climatic conditions and with different heaviness of the structures in Mediterranean climates. Regarding heating demand there was no sensible difference in the same location with massive or light structures. This is also in agreement with the most extensive and recent review on the thermal inertia of buildings [10]. The reported impact of thermal inertia on energy demand found in this work is relatively small. For residential buildings the energy savings reported are often in the order of magnitude of a few percent, which is far less pronounced than the impact of other energy saving measures such as increasing thermal insulation of the building envelope.

As for the radiant systems, in the past the works have been carried out especially under steady-state conditions. The most important steady-state parameters which describe the performance of radiant systems are heating/cooling capacity and thermal resistance [3,11,12]; however, steady-state analysis is not sufficient to describe the performance of radiant systems involving an important amount of thermal mass, like embedded surface systems and thermo-active building systems (TABS). Since the 1990s dynamic simulations have been carried out especially for the TABS which is a type of radiant system based on the thermal inertia of the structural slab [13]. For less massive radiant systems some works have been recently published looking at their behaviour in dynamic conditions, but the analyses mainly looked at the radiant system, without taking into account the room.

In particular, the influence of geometrical and construction parameters on the thermal performance of floor heating systems has been widely investigated, focusing mainly on wet systems, in which the pipes are embedded in a concrete layer. The pipe material, diameter and spacing, along with the thickness and material of the covering layer were studied, finding that the pipe material has negligible effect on the amount of useful heat [14], while the conductivity and thickness of the finishing layer have a high influence $[14,15]$. In the case of wood flooring, and also the installation method (floating or adhesive covering) was investigated [16]. While the pipe spacing and the mean value of the water 
temperature have large impacts on the surface temperature and heat transfer of the radiant floor, the thickness of the screed was found to have almost no influence [17].

Dry floor systems have been investigated less than wet systems. Experimental and numerical analysis of a lightweight system with aluminum foil covering a non-profiled insulation board were carried out by Zhang et al. [18], while the dynamic performance of a dry system with pipes laid in a profiled insulation board was investigated by Zhao et al. [19]. Qiu and Li [20] compared wet and dry floor systems based on numerical simulations, finding higher mean values, but lower uniformity, of the surface temperature of the dry system. Thomas et al. [21] developed a numerical model for the study of the steady-state and dynamic operation of a new light floor heating construction made of wood planks and aluminum diffuser, focusing also in this case only on the thermal behaviour of the emitter itself and stressing the importance of developing a model including also the building to fully investigate the performance of the radiant system and perform an energy comparison with traditional heating floor systems and other emission devices.

The present work hence looks at the overall balance of a room taking into account the thermal inertia of the radiant system as well as the water inside the pipes, as better described in detail hereafter. Usually for solving this problem dynamic simulations have to be run in order to properly take into account the dynamic behaviour of building structures, as well as transient operation of water in the embedded pipes. The heat conduction through the radiant systems can be modelled in different ways. The most widely used methods are the simplified RC-model [22] and the response factors technique [23]. Both models have been demonstrated to be accurate against measurements.

\section{Method}

The simulation of the dynamic behaviour of the considered radiant systems in different kinds of buildings has been carried out with the model DIGITHON [23]. This numerical model performs the detailed simulation of the dynamic behaviour of water-based surface heating and cooling systems. In the model DIGITHON, each surface of the room (containing pipes or not) is divided into elements named tiles (Figure 1); an overall heat balance is carried out for each element.

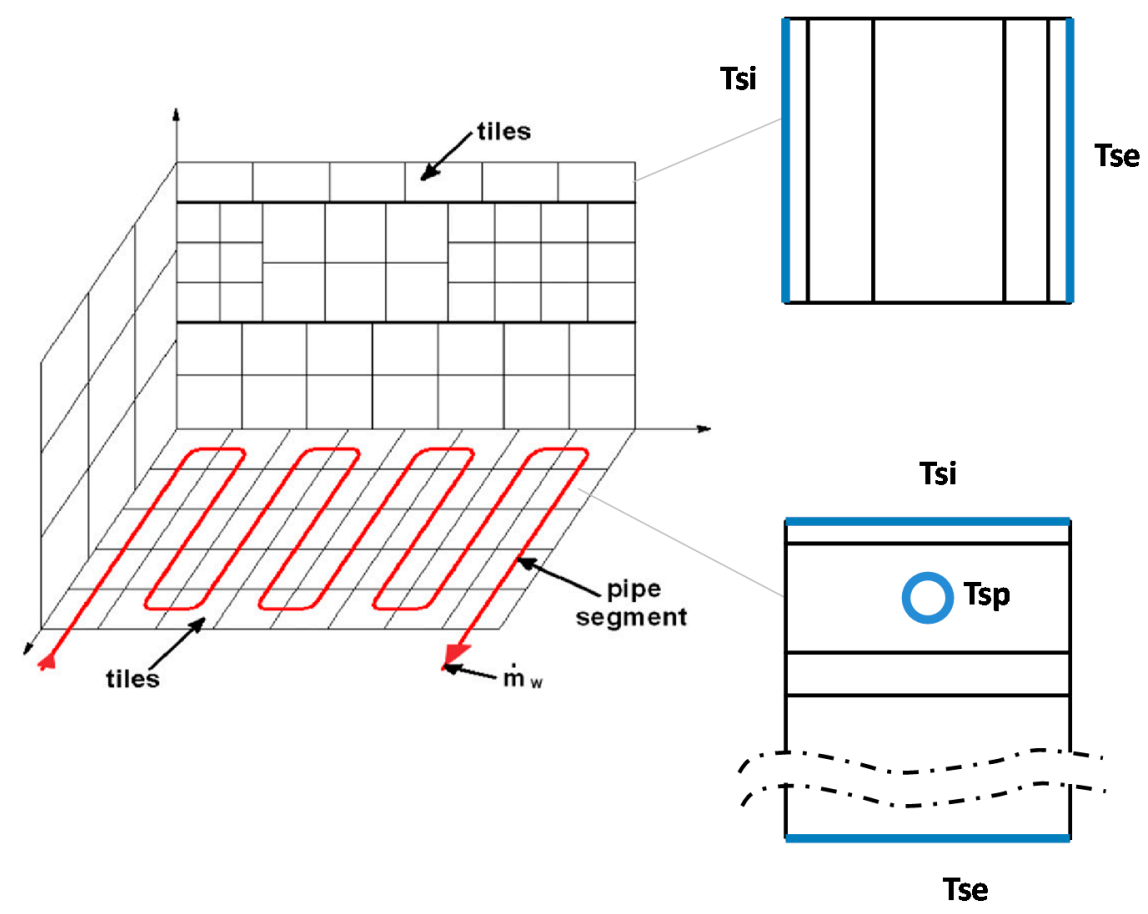

Figure 1. Example of discretization of a room equipped with a radiant system embedded in the floor [24] with the relevant surfaces where the heat balance is solved for structures with or without embedded pipes. 
To solve the dynamic conduction within the structures the "response factor" technique is used [24,25]. In the present work the heat transfer response factors are calculated by using the commercial software HEAT2 [26], which is based on the Finite Difference Method (FDM). Three simulations must be performed to describe the thermal conduction in a building structure with embedded pipes. In each simulation a triangular impulse of temperature is given on the inner surface, on the outer surface and on the internal surface of the pipes, thus the resulting heat flows on the three surfaces are recorded. After normalization, for a generic trend of temperature on the inner surface of the building structure, on the outer surface of the building structure and on the internal surface of the pipe, the response factor can be used, by superposing of effects, to calculate the specific heat fluxes on the three considered surfaces. More details about this method, included an example showing its accuracy, can be found in [27]. In case of building structures without embedded pipes, two simulations with triangular input have to be performed.

The convective heat flux for the $j$-th general surface element $q_{c, j}$ is expressed as:

$$
q_{c, j}=h_{c, j} S_{j}\left(T_{s, j}-T_{f, j}\right)
$$

where $T_{f, j}$ is the air temperature of the room (for the inner surface elements), the air temperature of the adjacent room (in case of internal walls) or the sol-air temperature (in case of outdoor surface). As for the air temperature, it can be assumed to be uniform when the room is less than $3 \mathrm{~m}$ height both in heating [28] and in cooling conditions [29] for radiant systems as well as in a wide range of situations that have been confirmed by other studies [30].

As for convective heat transfer coefficients, a recent review [31] shows that the most reliable analyses are those based on measurements in real size test rooms. In particular, as shown in [23], constant values can be considered for the convective heat exchange coefficients. For this purpose convective heat exchange coefficients have been assumed constant in the calculations.

As for the radiative heat exchange, assuming near-black surfaces, in the infrared with small temperature differences the mutual radiation with another surface can be written as:

$$
q_{r, j-k}=F_{j-k} 4 \sigma T_{m}^{3} S_{j}\left(T_{s, j}-T_{s, k}\right)=F_{j-k} h_{r, j-k} S_{j}\left(T_{s, j}-T_{s, k}\right)
$$

Since the surface discretisation is fine enough, in the model view factors $F_{j-k}$ are calculated in a detail way, as shown in [27].

Shortwave radiation entering from glazing elements has to be summed on the right side of Equation (2) as well as the internal radiant gains. As demonstrated in detail in [27] for cooling conditions and in [32] in heating period, there is no difference in the overall balance when considering solar radiation in detail or when it is assumed to be uniformly distributed. Hence, the solar radiation entering the room in the present work is considered as uniformly diffused.

For the room air, the following equation can be written as:

$$
\sum_{j=1, t}\left[h_{c, j} S_{j}\left(T_{s}-T_{a}\right)_{j}\right]+q_{I, c}=\frac{M_{a} c_{v}\left(T_{a}-\left(T_{a}\right)_{-\Delta \tau}\right)}{\Delta \tau}+\sum_{b} m_{b} c_{p} T_{b}
$$

where flow rates will enter at a given temperature (the external temperature for infiltration or a known inlet temperature for mechanical ventilation) and will leave at room temperature.

A similar equation can be written for the water inside each pipe segment. In this case, due to the discretisation, the temperature difference between two adjacent building elements can be considered very small, thus assuming a linear trend of the temperature in each building element. The 
representative water temperature is the outlet temperature of each element. Under these hypotheses the equation for the water can be written as follows:

$$
h_{c, w} S_{p}\left(T_{s, p}-T_{w}\right)=\frac{M_{w} c_{w}\left(T_{w}-\left(T_{w}\right)_{-\Delta \tau}\right)}{\Delta \tau}+\left|\dot{m}_{w}\right| c_{w}\left(T_{w, o}-T_{w, i}\right)
$$

where $T_{w, i}$ and $T_{w, o}$ are, respectively, the inlet and outlet temperatures in the pipe element. As for the water convection heat transfer coefficients inside the pipes correlations of literature are used [33].

All equations are linear, therefore the model can be expressed as a product of matrices which provides as results the inner side temperature and the heat flow of each surface element, the air temperature, and the return water temperature of the radiant system.

In the present work the FDM was also used to find the average value of the water temperature in the pipes of the radiant floor system which gives, in steady state conditions, a useful heat flux towards the heated room equal to the thermal losses in design conditions for heat transmission through the building structures, for infiltration and ventilation [34].

\section{Case Study}

\subsection{Building Geometry and Structures}

Simulations were carried out in a room with a floor area of $100 \mathrm{~m}^{2}$ (Figure 2). The windows are east and west oriented and their total surface is equal to $12.5 \mathrm{~m}^{2}$. The other two walls are adjacent to flats at the same temperature of the simulated one, as well as the ceiling and the floor. The case study represents a flat in an intermediate floor of a multi-story building. No internal walls were considered, therefore the entire space was simulated as a single room. Point $\mathrm{P}$, situated in the middle of the room at $1.10 \mathrm{~m}$ height from the floor, was considered for the evaluation of the operative temperature.
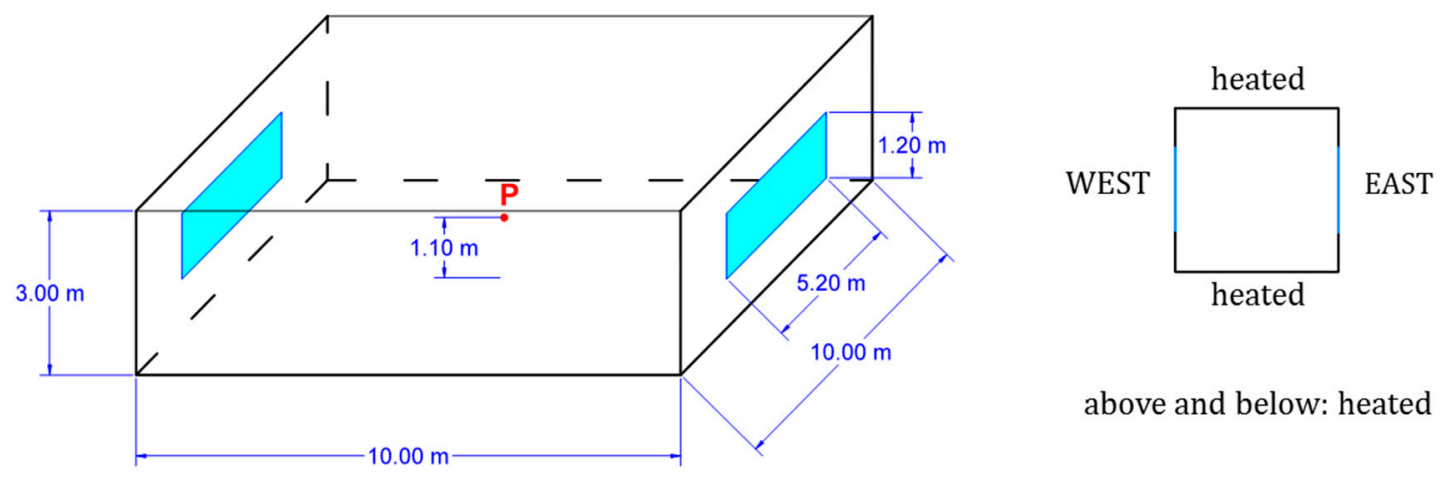

above and below: heated

Figure 2. The simulated room considered as case study.

The simulations were performed on an hourly basis, with the climatic TRY De Giorgio [35] of the city of Venice. In particular, the following hourly mean data were considered: air temperature, direct solar radiation, diffuse solar radiation and relative humidity, while the effect of wind on the infiltration was not taken into account. The official heating period defined by law for Venice has been considered, i.e. from mid-October to mid-April.

Eight types of building structures have been considered (Table 1): one type of stock building with a U-value of the walls equal to $1.3 \mathrm{Wm}^{-2} \mathrm{~K}^{-1}$, three types of insulated buildings with a U-value of about $0.5 \mathrm{Wm}^{-2} \mathrm{~K}^{-1}$ and four types of well-insulated buildings with a U-value ranging from 0.15 to $0.20 \mathrm{Wm}^{-2} \mathrm{~K}^{-1}$. The stratigraphies of the structures of each type of building, along with the thermal properties of each layer, are listed in Appendix A. Two kinds of windows were considered in this work, one for the buildings which are not insulated and a more performant one for all the other cases. The U-value of the window, the g-factor of the glass and the ratio between frame area and the entire window area are listed in Table 2. In order to have an overview of the room thermal characteristics, in 
Table 1 also the time constant $\tau$ of the external walls and the heat capacity $\mathrm{Cm}$ calculated according to EN ISO 13786 [36] are listed.

Table 1. Codification of the eight types of buildings simulated, time constant, and internal and external heat capacity of the outer walls.

\begin{tabular}{ccccc}
\hline Codification & Type of Building & $\boldsymbol{\tau} \mathbf{l h}]$ & $C_{m, i}\left[\mathbf{k J ~ m}^{-\mathbf{2}} \mathbf{K}^{-\mathbf{1}}\right]$ & $C_{m, e}\left[\mathbf{k J ~ m} \mathbf{~}^{-\mathbf{2}} \mathbf{K}^{-\mathbf{1}}\right]$ \\
\hline N & Non-insulated building & 101 & 61.3 & 97.6 \\
I-M & Insulated building-insulation in the middle of the wall & 210 & 52.5 & 95.4 \\
I-E & Insulated building-insulation on the external surface & 203 & 62.1 & 11.1 \\
I-I & Insulated building-insulation on the internal surface & 209 & 13.1 & 95.8 \\
WI-E & Well-insulated building-insulation on the external surface & 326 & 53.8 & 7.0 \\
WI-I & Well-insulated building-insulation on the internal surface & 575 & 10.1 & 102.2 \\
WI-X & Well-insulated building-cross laminated timber building & 809 & 17.4 & 121.7 \\
WI-L & Well-insulated building-light structure building & 87 & 14.5 & 31.3 \\
\hline
\end{tabular}

Table 2. Properties of the windows considered in this work.

\begin{tabular}{cccc}
\hline Type of Building & $U_{w}\left(\mathbf{W m}^{-\mathbf{2}} \mathbf{K}^{-1}\right)$ & $\mathbf{g}(-)$ & $A_{f} / A_{w}(-)$ \\
\hline N & 3.0 & 0.755 & 0.15 \\
I, WI & 1.5 & 0.600 & 0.15 \\
\hline
\end{tabular}

\subsection{Radiant Systems: Kinds and Circuits}

The eight kinds of building structures described above have been combined with the three kinds of radiant systems described in Figure 3 and Table 3. The stratigraphies of the radiant systems and the thermal properties of each layer can be found in the Appendix A.

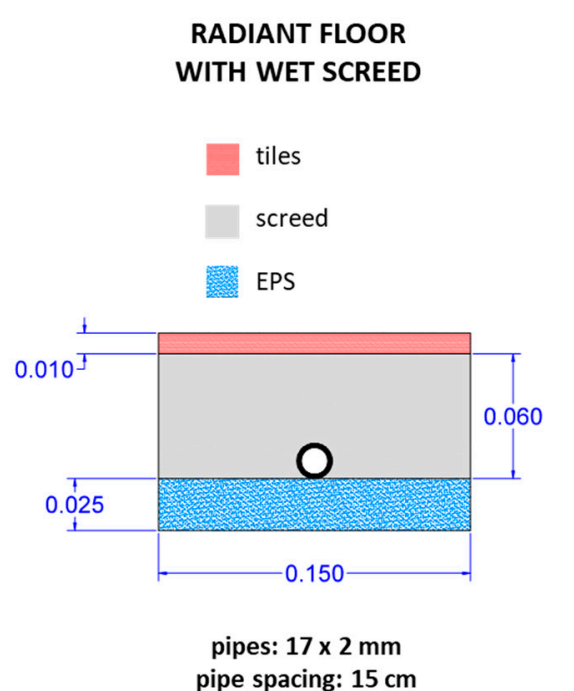

pipe spacing: $15 \mathrm{~cm}$
RADIANT FLOOR WITH DRY SCREED

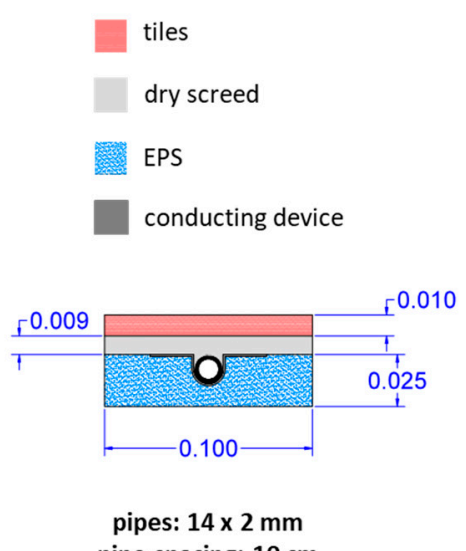

RADIANT CEILING

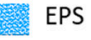

plasterboard

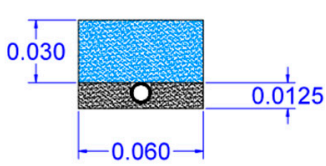

pipes: $10 \times 1 \mathrm{~mm}$ pipe spacing: $6 \mathrm{~cm}$

Figure 3. Description of the radiant systems considered in this work.

Table 3. Codification of the three types of radiant systems.

\begin{tabular}{ll}
\hline Codification & Type of Radiant System \\
\hline FW & Radiant floor with wet screed \\
FD & Radiant floor with dry screed and aluminum plate diffuser \\
C & Radiant ceiling with plasterboard coupled with insulation panels \\
\hline
\end{tabular}

For each kind of building the number of circuits of the radiant system was defined. The goal was to keep the pressure drop under $1 \mathrm{~m}$ w.c. The ceiling system was designed with 12 circuits, the floor system with dry screed with eight circuits and the floor system wet screed with six circuits. Only the floor systems in the building without insulation present a different number of circuits: 12 for the dry 
screed and eight for the wet screed, due to the high design heat load. The geometries of the different circuits are presented in Figure 4.

FW in all the buildings except for $\mathrm{N}$

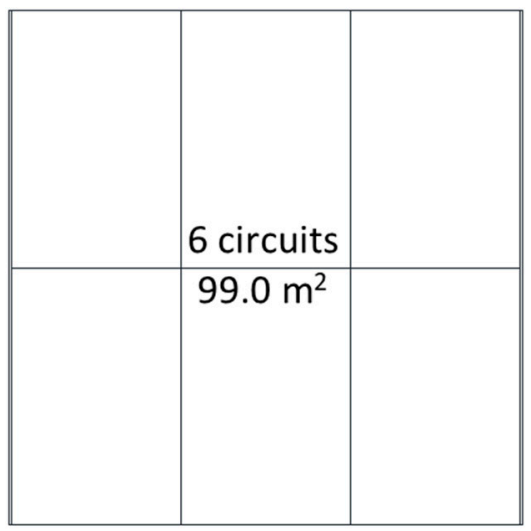

FD in all the buildings except for $\mathrm{N}$

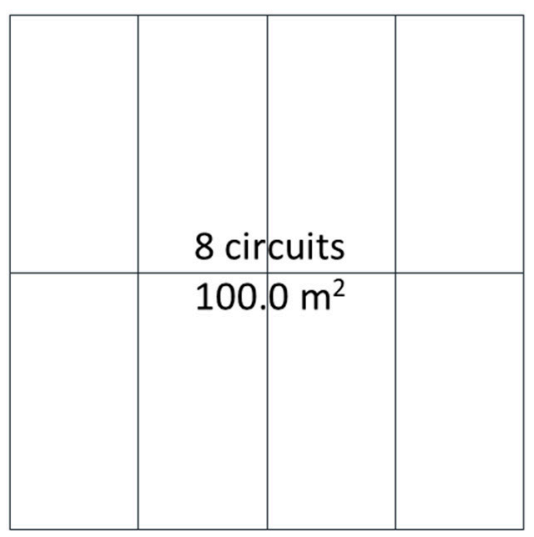

$C$ in all the buildings

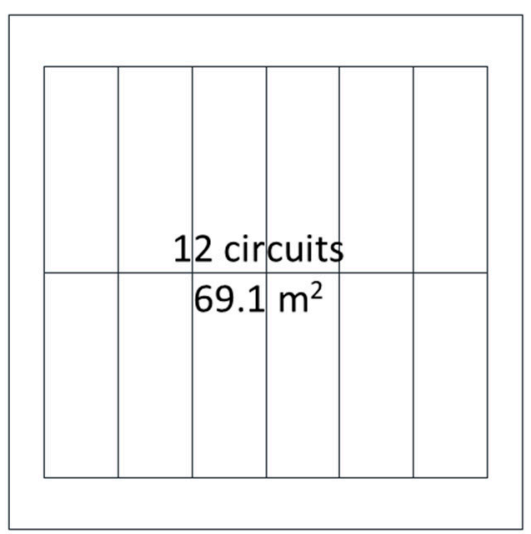

$\mathrm{FW}$ in $\mathrm{N}$

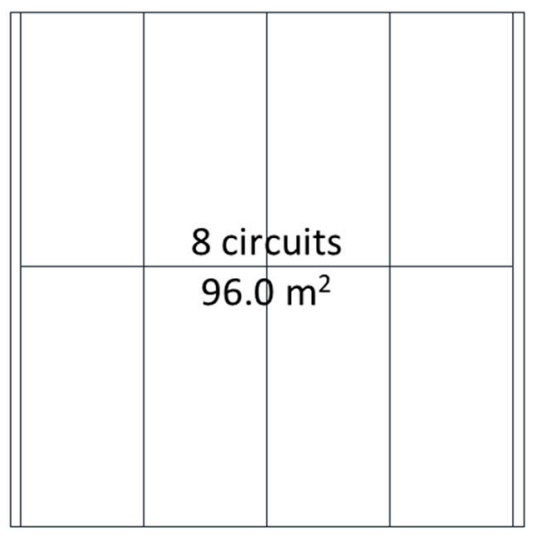

FD in $\mathrm{N}$

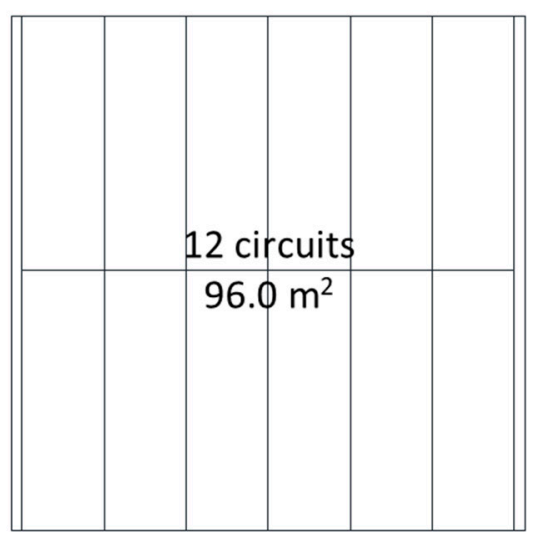

Figure 4. Number of circuits and active area of the radiant systems implemented in DIGITHON.

\subsection{Supply Water Temperature Control Modality}

Two operation modes were considered for the circuits of the radiant systems. First the simulations were done with a constant supply water temperature, regardless of external air temperature. Then a climatic control modality was implemented: the supply water temperature was set equal to the design value for an external air temperature up to $-5{ }^{\circ} \mathrm{C}$ (which is the design outdoor temperature for the 
considered climate) and a linear interpolation was done considering the value of $22.5^{\circ} \mathrm{C}$ for an external temperature of $20^{\circ} \mathrm{C}$.

The mean value of the water temperature circulating in the radiant system was obtained by means of HEAT2. As already explained, the desired temperature is that value which gives a heat flux towards the considered room equal to the specific design heating load. The design supply water temperature was set $2.5^{\circ} \mathrm{C}$ higher than that mean value (Table 4 ).

Table 4. Design heat load, specific heat load (per floor area) and supply water temperature evaluated considering a water temperature drop of $5^{\circ} \mathrm{C}$.

\begin{tabular}{cccccc}
\hline \multirow{2}{*}{ Type of Building } & \multicolumn{2}{c}{ Design Heat Load } & \multicolumn{2}{c}{ Water Temperature $\left({ }^{\circ} \mathbf{C}\right)$} & for Each Type of Radiant System \\
\cline { 2 - 6 } & $\mathbf{( k W )}$ & $\mathbf{( W ~ m}^{-\mathbf{2}} \mathbf{)}$ & $\mathbf{F W}$ & FD & $\mathbf{C}$ \\
\hline N & 3.77 & 37.7 & 29.8 & 28.6 & 35.7 \\
I-M & 2.39 & 23.9 & 27.1 & 26.4 & 30.8 \\
I-E & 2.29 & 22.9 & 26.9 & 26.2 & 30.5 \\
I-I & 2.28 & 22.8 & 26.9 & 26.2 & 30.5 \\
WI-E & 1.97 & 19.7 & 26.3 & 25.7 & 29.4 \\
WI-I & 1.98 & 19.8 & 26.3 & 25.7 & 29.4 \\
WI-X & 1.90 & 19.0 & 26.1 & 25.6 & 29.0 \\
WI-L & 1.94 & 19.4 & 26.2 & & 29.2 \\
\hline
\end{tabular}

An example of the different values of the mean water temperature required by the different kinds of radiant systems to heat the same building can be seen in Figure 5. It is useful to specify that, for the calculation of the specific heating load, the entire floor surface has been considered to be thermally active, against about $70 \%$ of the ceiling surface (according to water loops of Figure 4). For the heat loss calculation as well as FDM calculations in design conditions a temperature of $20^{\circ} \mathrm{C}$ has been set both in the heated room and in the rear room.
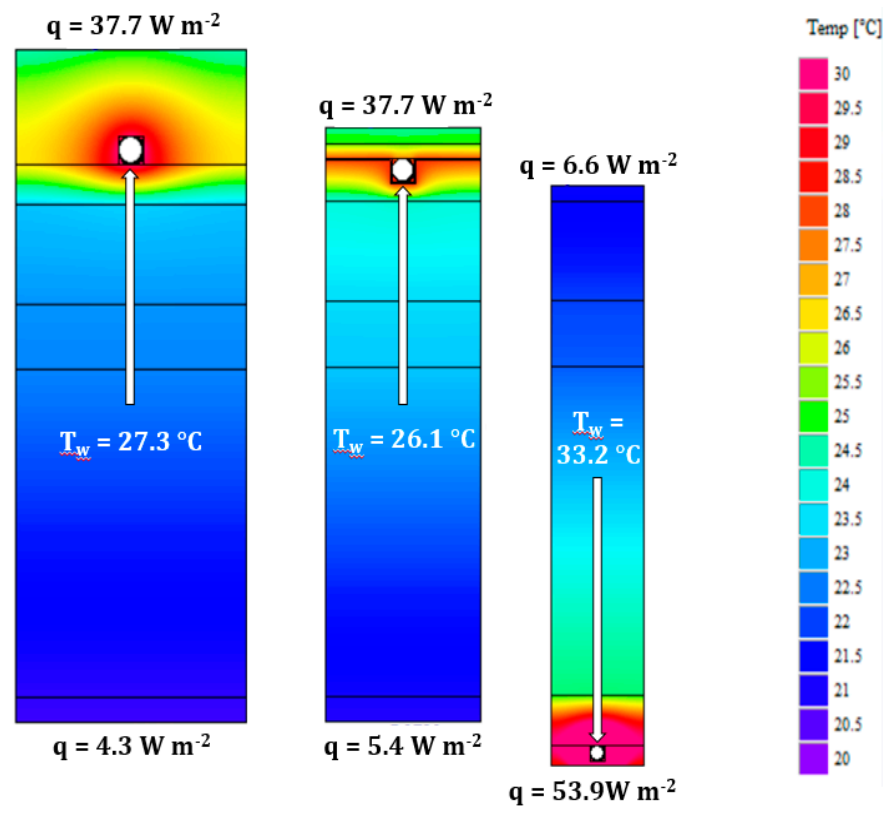

Figure 5. Example of calculation of the mean value of the water temperature required to fulfil the design heating load of the non-insulated building $(3770 \mathrm{~W})$ with the three different types of radiant systems. Average temperatures of the active surfaces are $23.4^{\circ} \mathrm{C}$ in the floor heating cases and $28.3^{\circ} \mathrm{C}$ in the case of radiant ceiling.

\subsection{Simulations Performed}

In order to evaluate the energy and comfort performance, three simulations were performed with DIGITHON for each combination of building structures and radiant systems: 
- an ideal convective simulation with air temperature set to $20.0^{\circ} \mathrm{C}$; and

- two radiant simulations with a reduced value of air temperature setting, so that the mean value of the operative temperature in the point $\mathrm{P}$ (in the middle of the room at $1.1 \mathrm{~m}$ height, as shown in Figure 2) in the period from December to February is the same of the ideal convective simulation. The radiant simulations were two because of the two examined control modalities of the supply water temperature (fixed and variable according to outdoor ambient temperature).

The air temperature setting and the resulting average operative temperature in the different types of buildings are shown in Table 5 .

Table 5. Mean value of operative temperature and air temperature setting of the radiant simulations.

\begin{tabular}{cccc}
\hline \multirow{2}{*}{ Building } & \multirow{2}{*}{$\boldsymbol{T}_{\boldsymbol{o}}\left({ }^{\circ} \mathbf{C}\right)$} & \multicolumn{2}{c}{$\boldsymbol{T}_{\text {air }}\left({ }^{\circ} \mathbf{C}\right)$} \\
\cline { 3 - 4 } & & FW, FD & $\mathbf{C}$ \\
\hline N & 19.4 & 19.3 & 18.8 \\
I-M, I-E, I-I & 19.8 & 19.7 & 19.4 \\
WI-E, WI-I & 20.0 & 19.8 & 19.6 \\
WI-X, WI-L & 20.0 & 19.7 & 19.6 \\
\hline
\end{tabular}

For the comfort analysis other 8 ideal convective simulations were done, one for each kind of building, removing the layers of the radiant system. In this way a comfort comparison was done between a building heated by a radiant system and the same building heated by an ideal convective system.

The external heat transfer coefficient of the external walls was set to $25 \mathrm{~W} \mathrm{~m}^{-2} \mathrm{~K}^{-1}$ and the solar absorption coefficient was set to 0.6 .

As found in a previous work [23], the choice of constant values for convective heat transfer coefficients instead of variable values implies negligible changes in the overall thermal balance calculated by DIGITHON. The convective heat transfer coefficient used for the different heated and unheated surfaces are reported in Table 6.

Table 6. Convective heat transfer coefficient of each surface of the room.

\begin{tabular}{cc}
\hline Surface & $\boldsymbol{\alpha}_{\boldsymbol{c}}\left(\mathbf{W} \mathbf{~ m}^{-\mathbf{2}} \mathbf{K}^{-\mathbf{1}}\right)$ \\
\hline Radiant floor & 5.5 \\
\hline Radiant ceiling & 1.0 \\
\hline Non-active surfaces & 2.5 \\
\hline
\end{tabular}

Infiltrations and internal gains (Table 7) have been maintained fixed in all the simulations.

Table 7. Other parameters of the simulations.

\begin{tabular}{ll}
\hline Parameter & \\
\hline Air change rate & $0.3 \mathrm{~h}^{-1}=90 \mathrm{~m}^{3} / \mathrm{h}$ (infiltrations + ventilation) \\
\hline Internal gains & $374 \mathrm{~W}, 70 \%$ convective and $30 \%$ radiant \\
\hline
\end{tabular}

\section{Results}

The software DIGITHON provides, in the case of ideal convective system, the thermal power needed in the time step to get the required air temperature. This means that the air temperature is fixed and heating is needed only if the air temperature could go below $20^{\circ} \mathrm{C}$ as calculated by the thermal balance. If the thermal balance leads to air temperatures greater than $20^{\circ} \mathrm{C}$ the air temperature is calculated as a result of the thermal balance. As results the surface temperatures are provided 
and, hence, the mean radiant temperature, as well as the operative temperature, can be calculated. The heating system has been considered to work constantly $24 \mathrm{~h}$, i.e. no overnight set-back has been assumed. The seasonal energy required by the ideal convective heating system has been named $Q_{i d}$.

When the simulation regards the radiant system, the inputs are the supply water temperature and the mass flow rate in each circuit, and the thermal balance gives as output the return temperature of the water; in this way the energy delivered/absorbed by the water in the time step can be evaluated, as well as the surface temperatures and, hence, the mean radiant and operative temperature. As already mentioned, the control system has been supposed to be on-off with a set-point of $20^{\circ} \mathrm{C}$ and a dead band of $\pm 0.5^{\circ} \mathrm{C}$. This means that if the temperature of the room in the time step is lower than $19.5^{\circ} \mathrm{C}$ the water circulates in the circuits with a defined supply temperature which could be fixed or variable as a function of external temperature. If the air temperature reaches $20.5^{\circ} \mathrm{C}$ the water stops circulating in the circuits and the temperature fluctuates depending on the thermal balance of the room without any active system working in that time step. As for the circuits in the room either all of them work or they do not operate, hence no zone control has been set since the room has been considered as an open space. From the hydronic point of view no other assumptions have been considered, such as a tank or a limiting power supplied by the generator, except for the water volume and related thermal capacity in the circuits in the room. The seasonal energy required by the water embedded heating system has been named $Q_{w}$.

The on-off control between $19.5^{\circ} \mathrm{C}$ and $20.5^{\circ} \mathrm{C}$ has been chosen based on a survey provided to companies producing radiant systems in Italy. All producers declared that in flats on-off regulation is the standard control strategy and that PI or PID control is only installed in single family houses due to the high costs of this latest technology.

\subsection{Radiant Systems Efficiency}

The hourly values of the energy provided as results of the simulations performed by DIGITHON permit the evaluation of the efficiency of the radiant system. Considering the seasonal energy $Q_{i d}$ of an ideal convective system and the seasonal energy provided to the radiant system $Q_{w}$, the efficiency of the radiant system can be defined as:

$$
\eta_{e m b+c t r l}=\frac{Q_{i d}}{Q_{w}}=\eta_{e m b} \cdot \eta_{c t r l}
$$

This is a joint embedded and control efficiency since it takes into account the losses of the radiant system behind the pipes as well as the effects of the control system. In Figure 6 the results obtained for the combination of eight building structures, three radiant systems, and two supply water temperature control modalities are represented. As already explained, these efficiency values are calculated along the whole heating season and hence they include the thermal inertia of the building structures, influence of solar and internal gains, the way the water circulating in the circuit is controlled as well as the heat losses in the room behind the radiant system. Since it is a combination of all these factors, it is not possible to split among a control efficiency and an embedded efficiency but they have to be considered together.

In the same figure, the steady-state embedded efficiency calculated through HEAT2 is represented in green colour. These efficiency values take into account only the geometry and the thermal properties of the building structure where the radiant system is placed and proper boundary conditions. Considering the useful thermal power $\phi_{u}$ towards the heated space and the thermal losses $\phi_{l}$ towards the adjacent space, the embedded efficiency in steady-state conditions of the radiant system can be calculated as:

$$
\eta_{e m b, H 2}=\frac{\phi_{u}}{\phi_{u}+\phi_{l}}
$$

The following boundary conditions were fixed: room temperatures equal to $20^{\circ} \mathrm{C}$, convective heat transfer coefficient on the surfaces according to Table 6 , adding the radiant heat transfer coefficient 
on the surfaces equal to $5.5 \mathrm{~W} \mathrm{~m}^{-2} \mathrm{~K}^{-1}$, water temperature according to the specific design heat load for each case (Table 4).

In order to maintain the same comfort conditions (i.e. same operative temperature), the radiant simulations were repeated reducing the air temperature set-point compared to the convective ideal simulation. As already mentioned, the set-point was chosen in such a way that the resulting mean value of the operative temperature in the point $\mathrm{P}$ in the period from December to February was the same of the mean value of the ideal convective simulations with set-point of the air $T_{\text {air }}=20^{\circ} \mathrm{C}$. This way an iterative process has been carried out for each single case in order to match the same operative temperature. The period from December to February has been chosen to evaluate the mean value of the operative temperature, because in the insulated building the average temperature in mild months is quite high, the heating system works rarely and it is difficult to compare buildings under the same operating conditions. In fact the heating energy need in the period December-February is, depending on the insulation level, from $75 \%$ to $90 \%$ of the total heating energy need of the buildings.

The embedded and control efficiency values for the radiant systems have been calculated via Equation (5). The results are shown for the period December-February (Figure 6), as well as for the whole season (Figure 7). As a matter of fact, the first value shows the results under the same indoor conditions (operative temperature), the second one gives an idea on the embedded and control efficiency over the whole season. In Figures 6 and 7 also the embedded values which can be calculated in steady state conditions by using Equation (6) with results of FDM are represented. This comparison has been carried out since the embedded emission according to EN 15316 [37] has to be calculated in steady state conditions as the ratio between the useful thermal input in the indoor environment and the overall power delivered by the water in the pipes. Even though they are calculated in steady state conditions they are then used in the energy performance of a building on a monthly or seasonal base. The analysis of EN 15316 will be considered again later, at the end of this paragraph.

As can be seen, the red line of the climatic control is on average slightly above the blue line of the constant supply temperature control modality. In well-insulated light buildings the efficiency is almost the same (98-99\%) regardless the type of radiant system used. These buildings present $2 \%$ higher efficiency compared to masonry structures; with these last structures there is no difference among radiant systems in climatic control strategy, while with constant temperature the wet floor performs slightly better. The results of well-insulated buildings of the period December-February (Figure 6) are very similar to the ones related to the whole season (Figure 7), since the energy evaluated in this period takes into account $90 \%$ of the heating demand of the whole season.

In non-insulated buildings and in insulated buildings usually the dry floor radiant system performs slightly worse than both the wet floor and the ceiling system (about $2 \%$ ). In these cases when considering the whole season instead of the period December-February there is a $2 \%$ difference in the embedded and control efficiency.

The interesting aspect is that the embedded and control efficiency calculated via dynamic simulations (Equation (5)) is higher than the embedded efficiency calculated via steady state conditions (Equation (6)). In light well-insulated structures the embedded and control efficiency of dynamic simulations is $1.5 \%$ better than the embedded efficiency estimated via FDM ( $1 \%$ if considering the period December-February, $2 \%$ if the whole season). In masonry well-insulated buildings the embedded and control efficiency of dynamic simulations is 3.5\% better than the embedded efficiency estimated via FDM with constant supply temperature ( $3 \%$ if considering the period December-February, $4 \%$ if the whole season), while dynamic simulations provide $4.5 \%$ better embedded and control efficiency than the embedded efficiency estimated via FDM in the case of climatic control ( $4 \%$ if considering the period December-February, $5 \%$ if the whole season). In insulated buildings the difference is almost $4 \%$ regardless to the water supply temperature, while for non-insulated buildings the difference is $6 \%$. It is useful to highlight that the efficiency calculated via FDM is evaluated with constant indoor temperature and in steady-state conditions, as usually done by producers of radiant systems and practitioners and, therefore, depends only on the difference between water temperature 
and room temperature and on the thermal conductivity of the materials of the various layers, but not on their thermal capacity. In dynamic conditions the situation is completely different, both for the water inside the pipes and for the boundary conditions. For most of the time the heat load required by the heated room is lower than the design heat load, and hence warm water is not continuously flowing in the pipes of the radiant system. The changing indoor conditions and the consequent on-off operation of the radiant system lead to a complex mechanism of absorption and release of heat in the different layers of the floor and the percentage losses results lower than in steady-state conditions. This means that part of the heat delivered by the pipes is absorbed by the layer containing them and, when water stops flowing, part of this becomes useful gain instead of backwards loss.

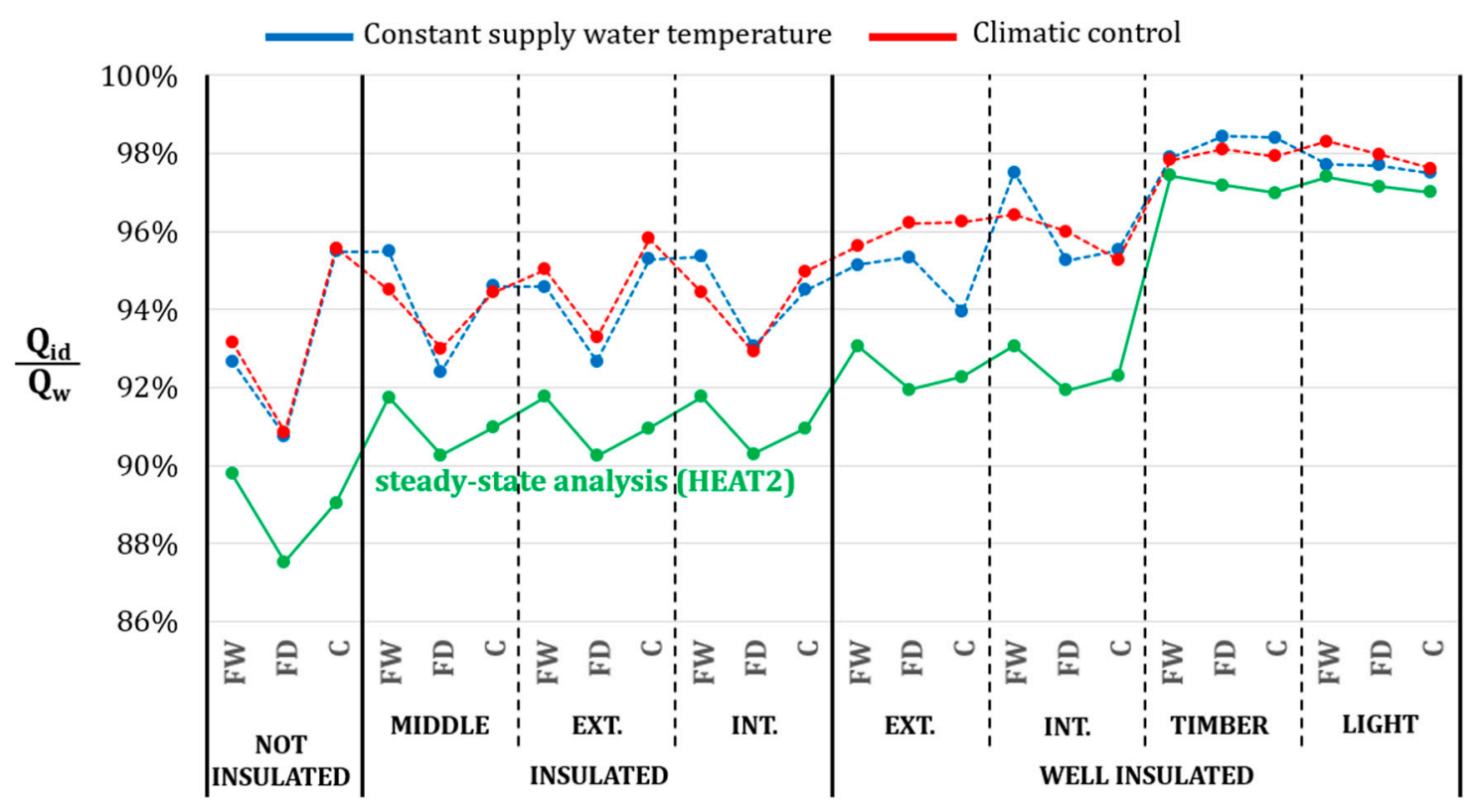

Figure 6. Efficiency of the radiant systems limited to the period from December to February, obtained considering the same operative temperature of the ideal convective simulations and (in green) efficiency calculated by FDM in steady-state conditions.

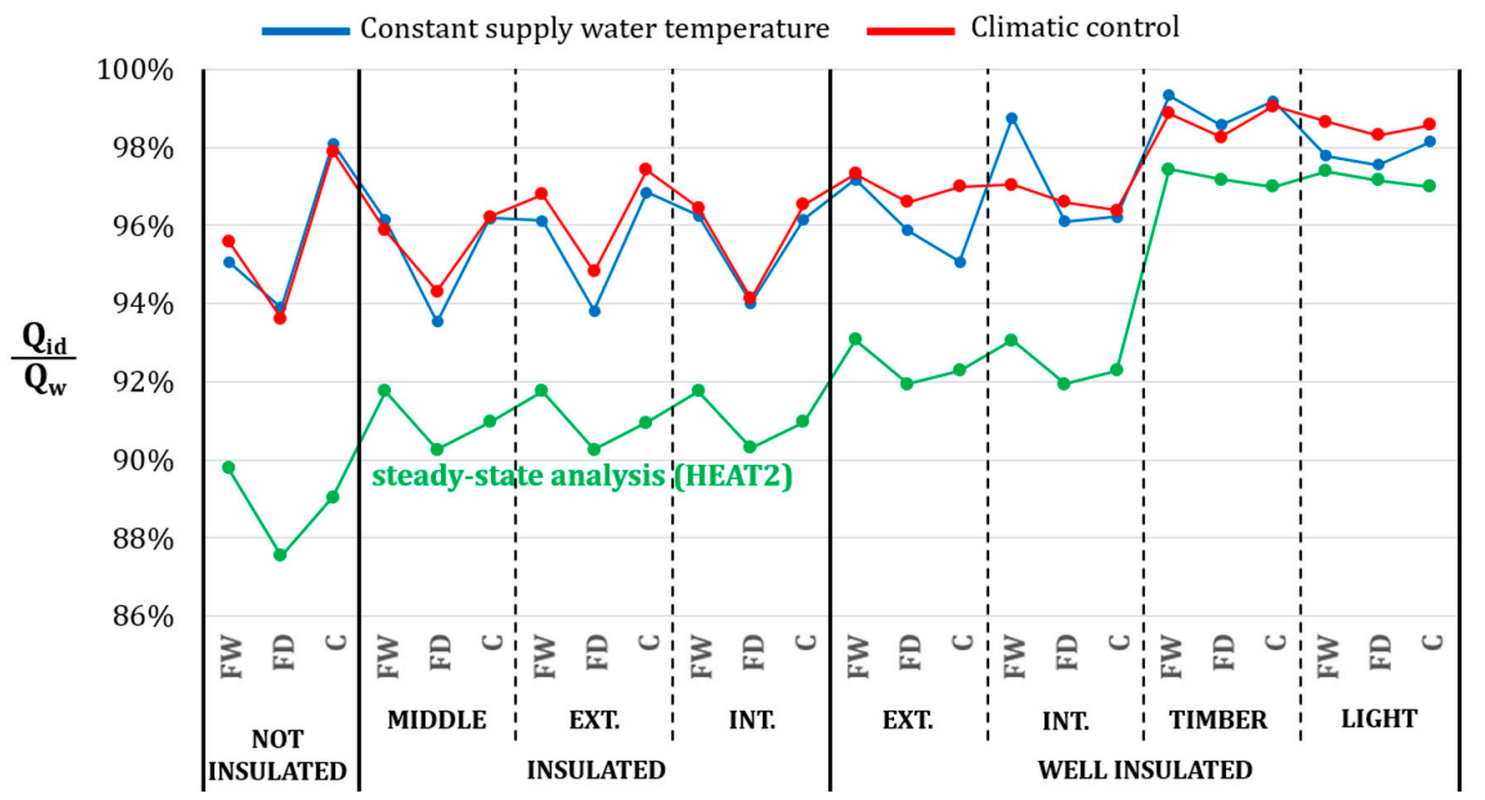

Figure 7. Efficiency of the radiant systems over the whole heating season and (in green) efficiency in steady-state conditions. 
As regards the efficiency values which can be found in the standards, the old version of EN ISO 15316-2-2007 [37] recommends to use an embedded and control efficiency value which is equal to $90 \%$ for the wet floor and ceiling systems $\left(\eta_{c t r}=0.95, \eta_{e m b}=0.94\right)$ considered in this study and $91.3 \%$ for the dry floor system $\left(\eta_{c t r}=0.95, \eta_{e m b}=0.955\right)$. No difference in the efficiency values in the old version of the standard is considered to take into account the different insulation level and thermal inertia of the building.

In the last version of the standard EN ISO 15316-2-2017 [38], the calculation method to evaluate the energy required by a heating or cooling system is only based on internal temperature variations, while the calculation method based on efficiency values was removed. Therefore, in the present work besides efficiency values, also the internal temperature variation was calculated from the results of the simulations for the period from December to February.

As can be seen in Table 8, the current standard overestimates the losses of the radiant systems: in the non-insulated case the difference is about $0.7^{\circ} \mathrm{C}$ for the radiant floor and $1.5^{\circ} \mathrm{C}$ for the ceiling. In insulated buildings the difference is $1.1^{\circ} \mathrm{C}$ in insulated buildings and $1.4^{\circ} \mathrm{C}$ for the radiant ceiling. In well-insulated masonry buildings the difference is $1.2 \div 1.5^{\circ} \mathrm{C}$ compared to the existing standard temperature variation for the radiant floor and $1.2{ }^{\circ} \mathrm{C}$ for the radiant ceiling. In well-insulated buildings with light structures the difference is about $1.7^{\circ} \mathrm{C} \div 2.0^{\circ} \mathrm{C}$ for the radiant floor, as well as for the radiant ceiling. These values are conservative since the calculation has been limited in the period December-February which is the one which provided the lowest efficiencies in terms of losses and hence the greatest values of the temperature difference $\Delta T_{i, e m b}+\Delta T_{i, c t r}$.

Table 8. Temperature variation values calculated from the results of the dynamic simulations with DIGITHON and values according to EN ISO 15316-2-2017.

\begin{tabular}{|c|c|c|c|c|}
\hline \multirow{3}{*}{ Type of Building } & \multirow{3}{*}{$\begin{array}{l}\text { Type of Radiant } \\
\text { System }\end{array}$} & \multicolumn{3}{|c|}{$\Delta T_{i, e m b}+\Delta T_{i, c t r}\left[{ }^{\circ} \mathrm{C}\right]$} \\
\hline & & \multicolumn{2}{|c|}{ Simulations } & \multirow[t]{2}{*}{ EN ISO 15316-2 } \\
\hline & & $\begin{array}{c}\text { Constant Supply } \\
\text { Water Temperature }\end{array}$ & Climatic Control & \\
\hline \multirow{3}{*}{$\mathrm{N}$} & FW & 1.1 & 1.1 & 1.9 \\
\hline & FD & 1.5 & 1.4 & 2.2 \\
\hline & $\mathrm{C}$ & 0.7 & 0.7 & 2.2 \\
\hline \multirow{3}{*}{ I-M } & FW & 0.7 & 0.9 & 1.9 \\
\hline & FD & 1.2 & 1.1 & 2.2 \\
\hline & $\mathrm{C}$ & 0.8 & 0.9 & 2.2 \\
\hline \multirow{3}{*}{ I-E } & FW & 0.8 & 0.8 & 1.9 \\
\hline & FD & 1.2 & 1.1 & 2.2 \\
\hline & $\mathrm{C}$ & 0.7 & 0.6 & 2.2 \\
\hline \multirow{3}{*}{ I-I } & FW & 0.7 & 0.9 & 1.9 \\
\hline & FD & 1.1 & 1.1 & 2.2 \\
\hline & $\mathrm{C}$ & 0.9 & 0.8 & 2.2 \\
\hline \multirow{3}{*}{ WI-E } & FW & 0.8 & 0.7 & 1.9 \\
\hline & FD & 0.7 & 0.6 & 2.2 \\
\hline & $\mathrm{C}$ & 1.0 & 0.6 & 2.2 \\
\hline \multirow{3}{*}{ WI-I } & FW & 0.4 & 0.6 & 1.9 \\
\hline & FD & 0.7 & 0.6 & 2.2 \\
\hline & $\mathrm{C}$ & 0.7 & 0.7 & 2.2 \\
\hline \multirow{3}{*}{ WI-X } & FW & 0.3 & 0.3 & 1.9 \\
\hline & FD & 0.2 & 0.3 & 2.2 \\
\hline & $\mathrm{C}$ & 0.2 & 0.3 & 2.2 \\
\hline \multirow{3}{*}{ WI-L } & FW & 0.4 & 0.3 & 1.9 \\
\hline & FD & 0.4 & 0.3 & 2.2 \\
\hline & $\mathrm{C}$ & 0.4 & 0.4 & 2.2 \\
\hline
\end{tabular}




\subsection{Energy Analysis}

In addition to the embedded and control efficiency, the overall energy consumption should also be evaluated. Concerning the supply water temperature control modality, the climatic control has the undeniable advantage of reducing its seasonal mean value of about $4{ }^{\circ} \mathrm{C}$ in non-insulated buildings, $2.5^{\circ} \mathrm{C}$ in insulated buildings, and $2{ }^{\circ} \mathrm{C}$ in well-insulated buildings (Figure 8 ). The ceiling systems need higher water temperatures than floor systems because of the lower convective heat transfer coefficient and of the smaller active surface; for this reason the ceiling systems show the greatest temperature reductions among the three kinds of radiant systems when going from the fixed temperature to variable supply temperature related to outside air (climatic control strategy). As regards the operation time, the climatic control obviously shows an increase, which is equal to $58 \%, 46 \%$ and $41 \%$ for the non-insulated, insulated and well-insulated buildings respectively.

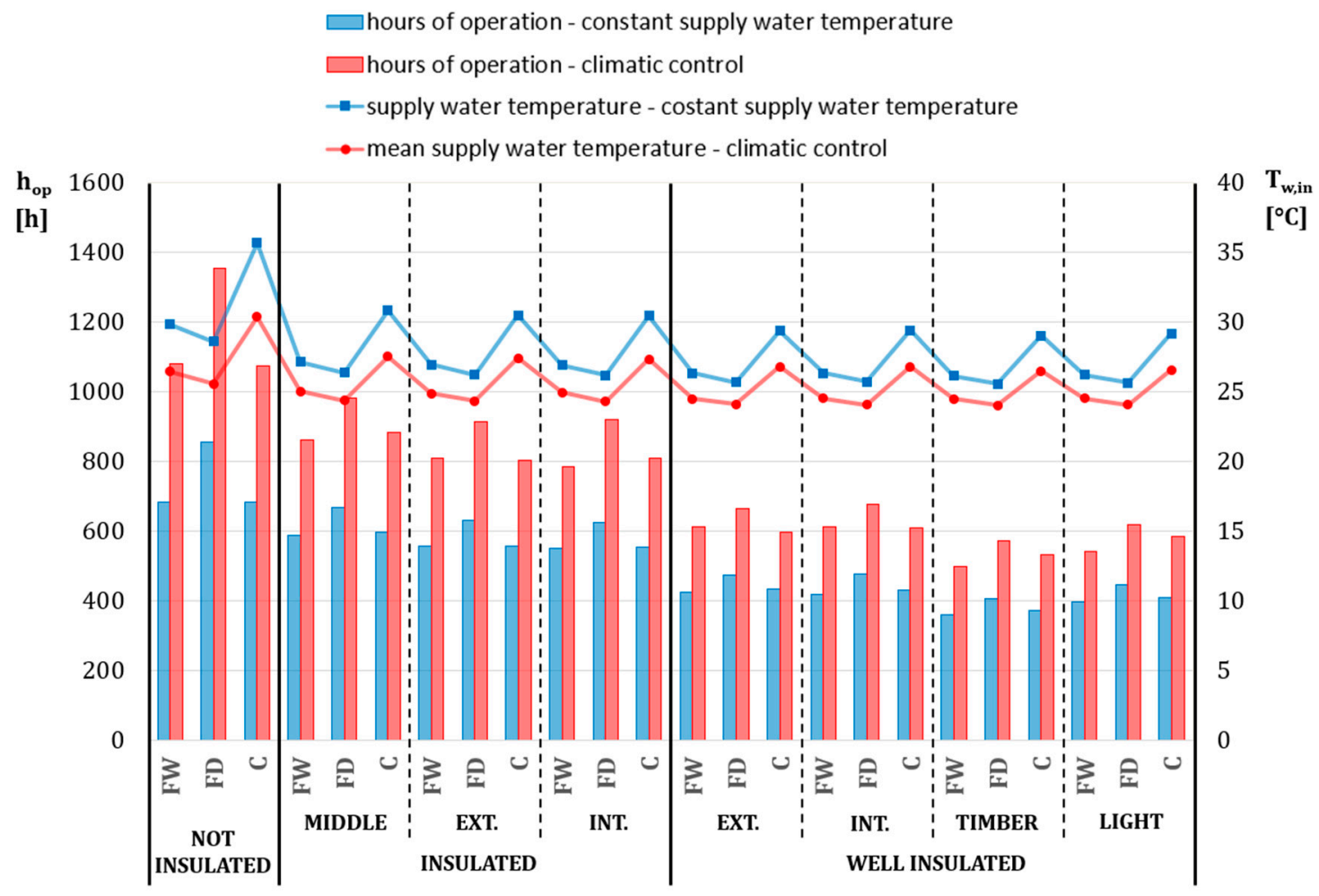

Figure 8. Hours of operation of the radiant systems and mean value of the supply water temperature in the different cases.

A simplified evaluation of the energy consumption of the entire heating system was done considering a water-to-water heat pump as generator, a primary loop, and a secondary loop with their pumps (Figure 9).

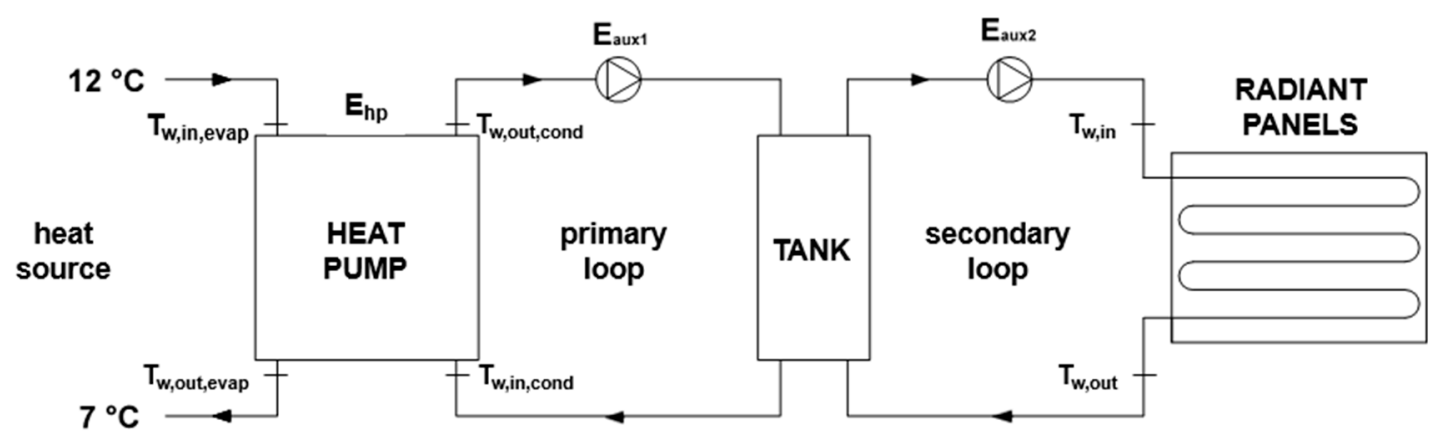

Figure 9. Simplified layout of the considered heating system. 
The electric energy consumption of the heat pump was estimated considering a heat source constantly at $12{ }^{\circ} \mathrm{C}$ and a temperature difference at the evaporator of $5^{\circ} \mathrm{C}$ (water source temperature from $12{ }^{\circ} \mathrm{C}$ to $7^{\circ} \mathrm{C}$ ). The nominal conditions in Table 9 from a commercial datasheet were considered to evaluate the coefficient of performance (COP).

Table 9. Nominal data of the considered water-to-water heat pump.

\begin{tabular}{cccc}
\hline \multicolumn{2}{c}{ Heat Pump Data } & \multicolumn{3}{c}{ Nominal Condition } \\
\hline$P_{\text {el,nom }}$ & $1.6 \mathrm{~kW}$ & $T_{w, \text { in }, \text { evap }}=12{ }^{\circ} \mathrm{C}$ & $T_{w, \text { out }, \text { evap }}=5{ }^{\circ} \mathrm{C}$ \\
$P_{t, \text { nom }}$ & $6.8 \mathrm{~kW}$ & $T_{w, \text { in cond }}=30^{\circ} \mathrm{C}$ & $T_{w, \text { out cond }}=35^{\circ} \mathrm{C}$ \\
$\mathrm{COP}_{\text {nom }}$ & 4.25 & & \\
\hline
\end{tabular}

For evaluating the COP of the heat pump the ideal coefficient of performance of a Carnot cycle has been used:

$$
C O P_{i d}=\frac{T_{\text {cond }}}{T_{\text {cond }}-T_{\text {evap }}}
$$

where the condensing and evaporating temperatures of the cycle have been evaluated as follows:

$$
\begin{gathered}
T_{\text {cond }}=\frac{T_{w, \text { in }, \text { cond }}+T_{w, \text { out }, \text { cond }}}{2}+5 \\
T_{\text {evap }}=\frac{T_{w, \text { in }, \text { evap }}+T_{w, \text { out }, \text { evap }}}{2}-5
\end{gathered}
$$

By using Equations (3)-(5), in nominal condition the ideal Carnot cycle gives $C O P_{i d, n o m}=9.41$. At each time step of the simulations the ideal coefficient of performance $C O P_{i d}$ was calculated considering the mean value of the water temperature in the condenser equal to the supply water temperature $T_{w \text {, in }}$ of the radiant panels. The COP of the heat pump was then estimated as follows:

$$
C O P=C O P_{i d} \frac{C O P_{\text {nom }}}{C O P_{i d, n o m}}
$$

At each timestep the electric energy consumption of the heat pump $E_{h p}$ can be calculated as:

$$
E_{h p}=\frac{Q_{w}}{C O P}
$$

From the seasonal thermal energy and the corresponding electric consumption, the mean value of the COP can be calculated. This is called seasonal performance factor, SPF, and its value can be seen in Figure 10 (right axis) together with the electric energy require by the heat pump (left axis).

The higher SPF which can be achieved with the climatic control of the supply water temperature makes the heat pump electric consumption lower, but also the electric consumption of the auxiliaries should be evaluated. As already seen in Figure 8, the number of hours of operation of the pump of the secondary loop is much higher in the case of climatic control instead of constant supply water temperature. The pressure drops of each combination of radiant system and building type were calculated and the electric power of the pump was then evaluated from the chart of a common high efficiency pump for domestic use. For the primary loop the number of hours of operation of the pump was calculated from the seasonal thermal energy need and the nominal thermal power of the heat pump.

The resulting total electric energy consumption $E_{\text {tot }}$ can be seen in Table 10, where also the electric energy consumption of the heat pump $E_{h p}$, of the primary pump $E_{a u x, 1}$ and of the secondary pump $E_{a u x, 2}$ are listed. 


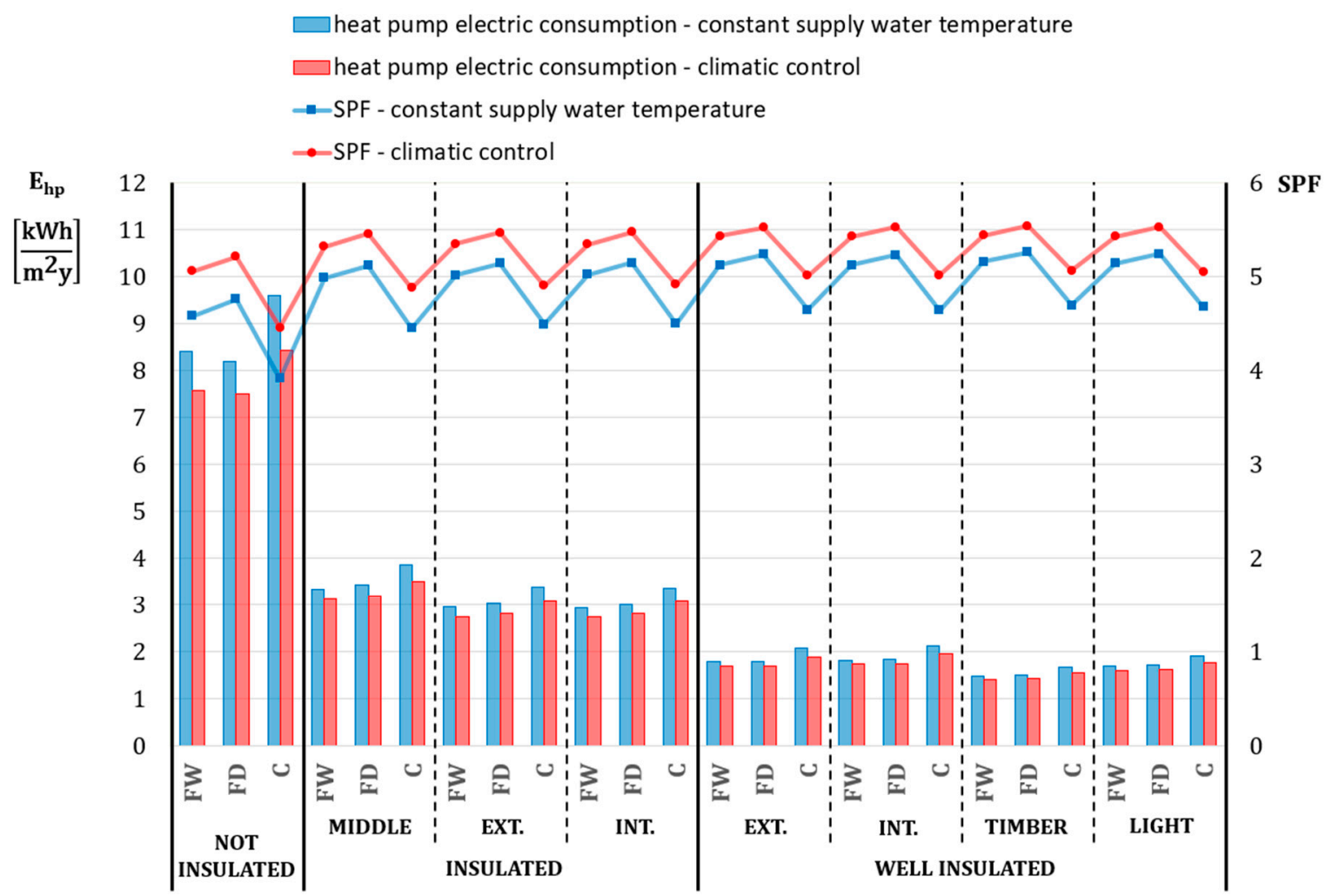

Figure 10. Heat pump electric energy consumption and seasonal performance factor with constant supply water temperature and climatic control.

Table 10. Electric energy consumptions and percentage difference between climatic control and constant supply water temperature.

\begin{tabular}{|c|c|c|c|c|c|c|c|c|c|c|}
\hline \multirow{2}{*}{$\begin{array}{c}\text { Type of } \\
\text { Building }\end{array}$} & \multirow{2}{*}{$\begin{array}{l}\text { Type of } \\
\text { Radiant } \\
\text { System }\end{array}$} & \multicolumn{4}{|c|}{ Constant Supply Water Temperature } & \multicolumn{4}{|c|}{ Climatic Control } & \multirow{2}{*}{$\Delta E_{t o t}$} \\
\hline & & $\begin{array}{c}E_{h p} \\
\text { (kWh) }\end{array}$ & $\begin{array}{l}E_{\text {aux } x, 1} \\
\text { (kWh) }\end{array}$ & $\begin{array}{l}E_{a u x, 2} \\
\text { (kWh) }\end{array}$ & $\begin{array}{c}E_{t o t} \\
\text { (kWh) }\end{array}$ & $\begin{array}{c}E_{h p} \\
\text { (kWh) }\end{array}$ & $\begin{array}{l}E_{\text {aux } x, 1} \\
\text { (kWh) }\end{array}$ & $\begin{array}{l}E_{\text {aux }, 2} \\
\text { (kWh) }\end{array}$ & $\begin{array}{c}E_{t o t} \\
(\mathbf{k W h})\end{array}$ & \\
\hline \multirow{3}{*}{$\mathrm{N}$} & FW & 841 & 31 & 11 & 883 & 757 & 31 & 17 & 806 & $-8.7 \%$ \\
\hline & FD & 820 & 32 & 16 & 868 & 750 & 32 & 26 & 807 & $-6.9 \%$ \\
\hline & $\mathrm{C}$ & 960 & 30 & 13 & 1003 & 844 & 30 & 21 & 896 & $-10.8 \%$ \\
\hline \multirow{3}{*}{$\mathrm{I}-\mathrm{M}$} & FW & 333 & 13 & 4 & 351 & 313 & 13 & 6 & 333 & $-5.1 \%$ \\
\hline & FD & 342 & 14 & 8 & 365 & 318 & 14 & 12 & 344 & $-5.6 \%$ \\
\hline & $\mathrm{C}$ & 385 & 14 & 7 & 406 & 351 & 14 & 11 & 375 & $-7.6 \%$ \\
\hline \multirow{3}{*}{ I-E } & FW & 295 & 12 & 4 & 311 & 275 & 12 & 6 & 293 & $-5.9 \%$ \\
\hline & FD & 303 & 13 & 7 & 323 & 282 & 12 & 10 & 304 & $-5.6 \%$ \\
\hline & $C$ & 338 & 12 & 6 & 356 & 307 & 12 & 9 & 329 & $-7.7 \%$ \\
\hline \multirow{3}{*}{ I-I } & FW & 292 & 12 & 4 & 308 & 274 & 12 & 5 & 291 & $-5.3 \%$ \\
\hline & FD & 300 & 12 & 7 & 319 & 281 & 12 & 10 & 304 & $-4.8 \%$ \\
\hline & $\mathrm{C}$ & 337 & 12 & 6 & 355 & 307 & 12 & 9 & 329 & $-7.6 \%$ \\
\hline \multirow{3}{*}{ WI-E } & FW & 179 & 7 & 3 & 189 & 169 & 7 & 4 & 180 & $-4.9 \%$ \\
\hline & FD & 180 & 8 & 4 & 191 & 169 & 8 & 5 & 182 & $-4.8 \%$ \\
\hline & $\mathrm{C}$ & 208 & 8 & 4 & 220 & 189 & 8 & 5 & 202 & $-8.1 \%$ \\
\hline \multirow{3}{*}{ WI-I } & FW & 181 & 7 & 3 & 191 & 173 & 8 & 4 & 185 & $-3.1 \%$ \\
\hline & FD & 184 & 8 & 4 & 196 & 173 & 8 & 6 & 187 & $-4.6 \%$ \\
\hline & $\mathrm{C}$ & 212 & 8 & 4 & 223 & 196 & 8 & 5 & 209 & $-6.4 \%$ \\
\hline \multirow{3}{*}{ WI-X } & FW & 148 & 6 & 2 & 156 & 141 & 6 & 3 & 150 & $-4.0 \%$ \\
\hline & FD & 151 & 6 & 3 & 160 & 143 & 6 & 4 & 154 & $-3.7 \%$ \\
\hline & $\mathrm{C}$ & 168 & 6 & 3 & 177 & 156 & 6 & 4 & 167 & $-6.0 \%$ \\
\hline \multirow{3}{*}{ WI-L } & FW & 170 & 7 & 2 & 179 & 159 & 7 & 3 & 170 & $-5.4 \%$ \\
\hline & FD & 171 & 7 & 4 & 182 & 161 & 7 & 5 & 173 & $-4.8 \%$ \\
\hline & C & 191 & 7 & 3 & 202 & 176 & 7 & 5 & 189 & $-6.6 \%$ \\
\hline
\end{tabular}


If the generator of the heating system is a heat pump and the radiant circuits are properly designed, the increase of the operation time of the secondary loop with climatic control instead of constant supply water temperature is in any case balanced by the reduction of the consumption of the heat pump due to the lower water temperature. Considering the ceiling system, the climatic control modality ensures a reduction of the total electric energy consumption of about $11 \%, 8 \%$, and $7 \%$ for the non-insulated, insulated and well-insulated buildings, respectively. With the floor systems the reduction is about $8 \%$, $5 \%$, and $4 \%$, respectively.

\subsection{Overtemperature Analysis}

An analysis was carried out on the operative temperature in the point $\mathrm{P}$ (Figure 2) in the period from December to February, considering the degree hours criteria described in Annex F of EN 15251 (2007) [39]. A temperature range was defined and the degree hours outside the upper boundary of the range $\left(T_{u l}\right)$ was used as a performance indicator of the building for the heating season in relation to the overtemperature. The weighting time for overtemperature $\mathrm{WF}^{+}$can be calculated as:

$$
\mathrm{WF}^{+}=\sum\left(T_{o}-T_{o, u l}\right) \text { for } T_{o}>T_{o, u l}
$$

Since the simulations have been performed maintaining in the convective ideal case the air temperature constant at $20^{\circ} \mathrm{C}$, the operative temperature differs in all cases. Hence, a specific range was defined for each radiant case, centred on the mean value of the operative temperature, which is the same of the ideal convective cases, and with an amplitude of $1.0^{\circ} \mathrm{C}$ (i.e. $\pm 0.5^{\circ} \mathrm{C}$ ). A small band was chosen, with the same amplitude of the on-off thermostat, since the purpose was not the evaluation of comfort conditions, but simply the evaluation of the periods with the operative temperature rising outside the control band of the air temperature and the comparison of these periods with different envelopes and type of radiant systems, as well as the comparison between the building with the radiant systems and the same building with an ideal convective heating system. A larger band was not suitable for a fully exhaustive evaluation for this purpose, since it was found that, in the worst cases (well-insulated timber envelope and light envelope with dry floor system), the operative temperature exceeded more than $1.5^{\circ} \mathrm{C}$ its mean value for only about $3 \%$ of the time, i.e. no discomfort has been found for overheating in all the cases.

In Figure 11 the $\mathrm{WF}^{+}$calculated from the results of the radiant simulations are represented. As can be noticed, the constant supply water temperature control modality always gives a higher $\mathrm{WF}^{+}$than the climatic control modality, except for the well-insulated buildings, where the $\mathrm{WF}^{+}$are similar. The ceiling systems present a $\mathrm{WF}^{+}$which is, on average, more than five times the $\mathrm{WF}^{+}$of the floor systems in the non-insulated building and 2.5 times in the insulated and well-insulated masonry buildings. In the well-insulated lighter buildings the dry-floor system presents the highest $\mathrm{WF}^{+}$, almost 1.5 times the $\mathrm{WF}^{+}$of the wet-floor and ceiling systems.

It is interesting to notice that the $50 \%$ of the $\mathrm{WF}^{+}$of the well-insulated light buildings can be already found in the ideal convective simulations. This percentage decreases to $27 \%$ for the well-insulated masonry buildings, $12 \%$ percent for the insulated buildings and only $2 \%$ for the non-insulated buildings. In a convective system controlled with an on-off band like the simulated radiant systems, these percentages would certainly be higher, showing that the problem of overtemperature in well-insulated buildings is not strictly related to the radiant system itself, but it is inevitable especially in the case of light structures (even in ideal conditions); secondly, the control modality may affect the overtemperature.

In Figure 12 the value $\mathrm{WF}^{+} / \mathrm{h}^{+}$of the overtemperature is represented; $\mathrm{h}^{+}$is the number of hours which contribute to the overall value of $\mathrm{WF}^{+}$, i.e., the number of hours in which the operative temperature exceeds the threshold value defined; this parameter can be named overtemperature intensity. In the insulated buildings the overtemperature intensity is the same of the ideal convective cases, except for the constant supply water temperature ceiling systems which show much higher 
values. The well-insulated masonry buildings with wet-floor radiant system show an overtemperature intensity lower than that of the ideal convective system. The same occurs in the well-insulated light buildings for the wet floor radiant systems and also for the ceiling systems, but not for the dry-floor systems.

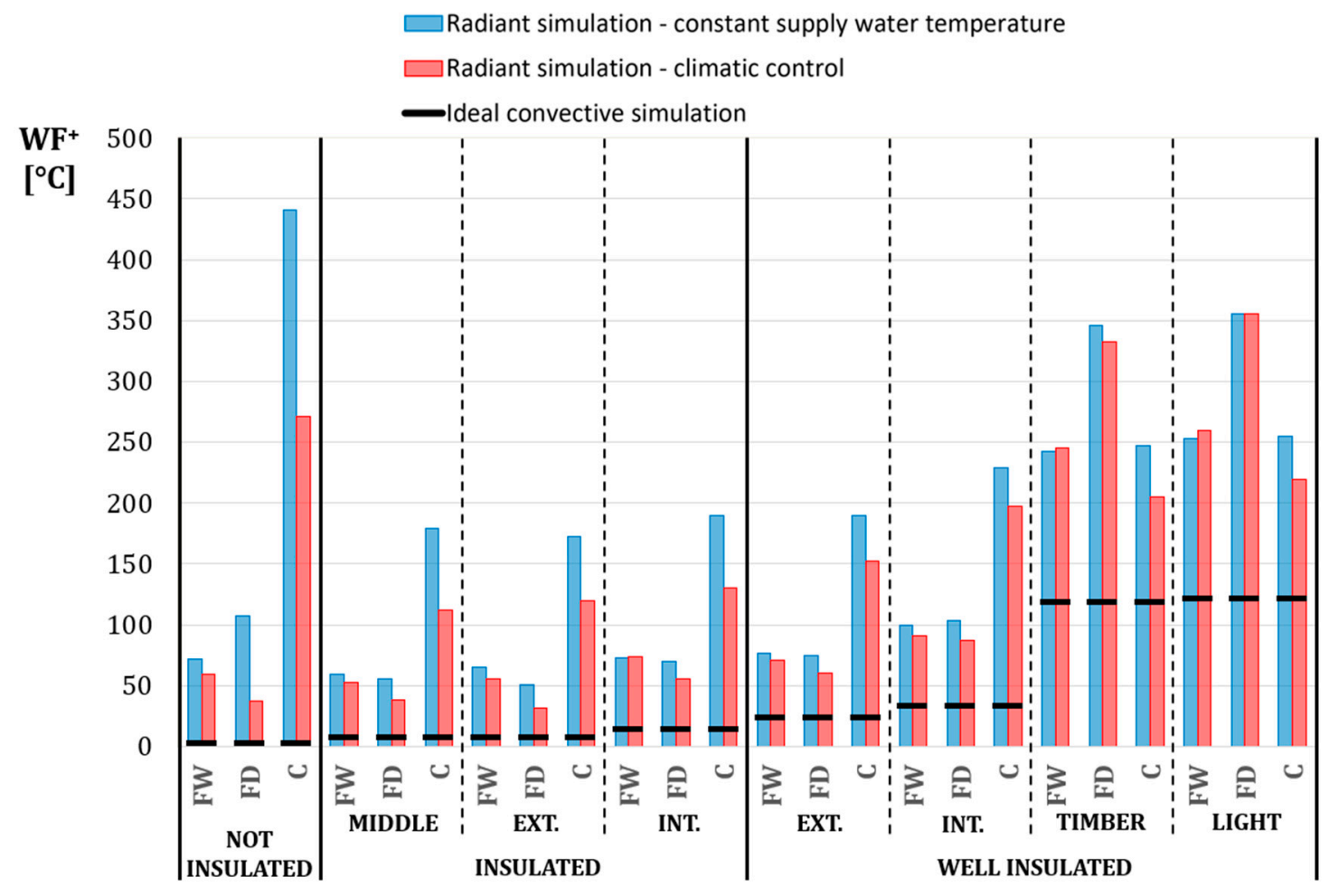

Figure 11. Weighed time in the radiant cases and in the equivalent ideal convective ones.

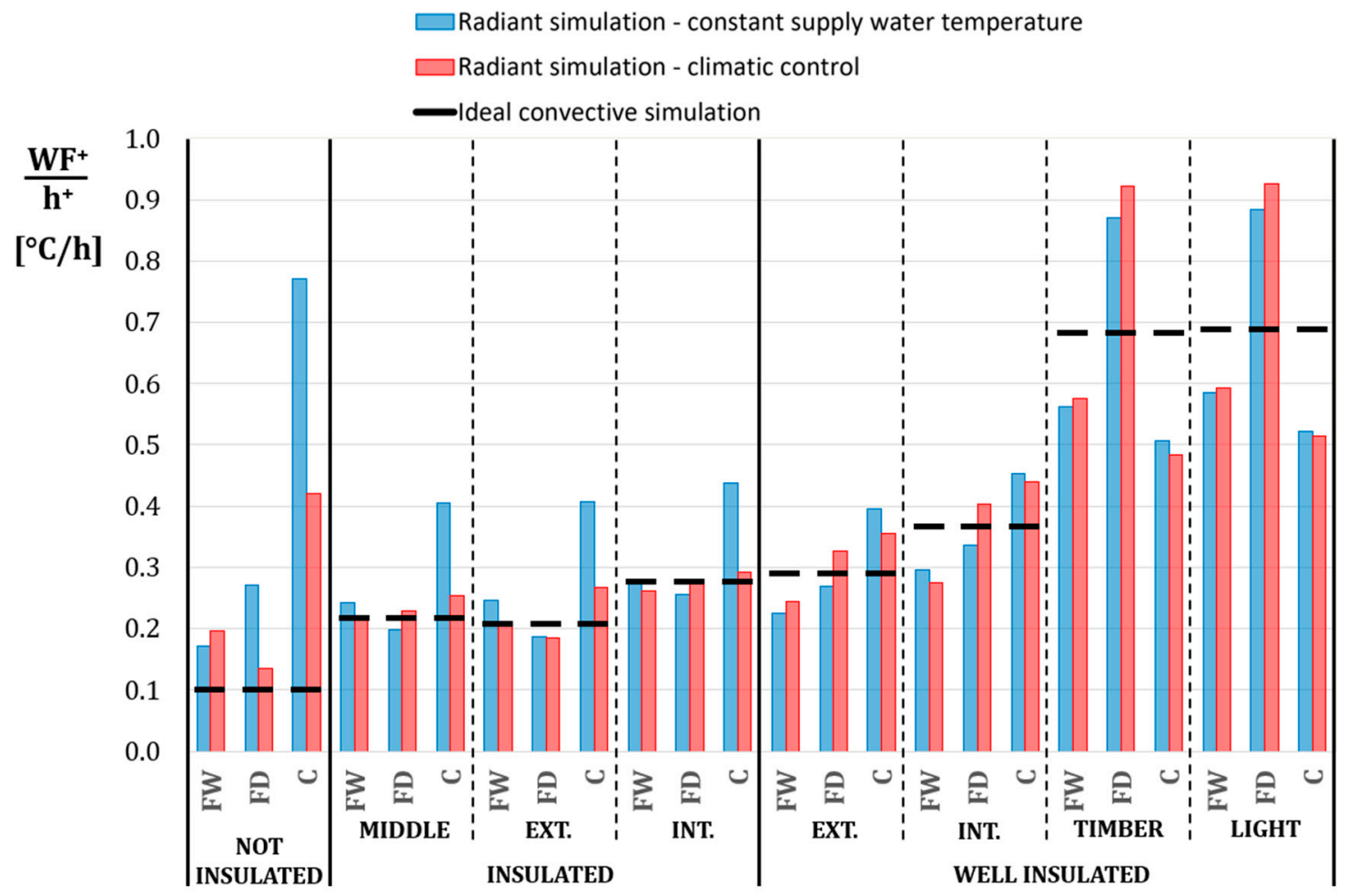

Figure 12. Mean value of the specific overtemperature in the radiant cases and in the equivalent ideal convective ones. 


\section{Conclusions and Discussion}

The work carried out is based on simulation of a room which represents an intermediate multi-story flat of about $100 \mathrm{~m}^{2}$ where three types of radiant systems have been modelled: two radiant floors (one with usual pipes embedded in wet screed and one with low thickness dry screed) and a radiant ceiling. The work looks at the performance of these systems in heating conditions with three insulation levels of buildings: no insulation, insulated building and well-insulated building. Three types of insulated buildings (with internal, intermediate, and external insulation) and four types of well-insulated buildings (masonry with external and internal insulation, timber structure, and light structure) have been analysed. Dynamic simulations of the radiant systems with fixed temperature and with variable temperature according to outdoor temperature have been compared with an ideal convective dynamic simulation.

Results have been analysed in terms of control and embedded efficiency of the radiant system, energy performance of the radiant system with a water to water heat pump at fixed source temperature, as well as possible overtemperature.

About the embedded and control efficiency, the climatic control strategy performs slightly better than the constant supply temperature control modality. In well-insulated light buildings the efficiency of the two control strategies is almost the same (98-99\%) regardless of the type of radiant system used. These buildings present a $2 \%$ higher efficiency compared to masonry structures, with these last structures the different types of radiant systems show the same efficiency value in case of climatic control strategy, while with constant temperature the wet floor performs slightly better. In non-insulated buildings and in insulated buildings usually the dry floor radiant system performs about $2 \%$ less than both the wet floor and the ceiling system (which present circa $96 \%$ of efficiency).

The embedded and control efficiency calculated via dynamic simulations has been compared to the embedded efficiency calculated via steady state conditions. In light well-insulated structures the embedded and control efficiency of dynamic simulations is $1.5 \%$ better than the one estimated via FDM. In masonry well-insulated buildings the embedded and control efficiency of dynamic simulations is $3.5 \%$ better than the one estimated via FDM with constant supply temperature, while climatic control simulations provide $4.5 \%$ better embedded and control efficiency than the one estimated via FDM. In insulated buildings the difference is almost $4 \%$ regardless to the water supply temperature, while for non-insulated buildings the difference is $6 \%$.

The old version of the standard EN15316-2-2007 [37] provides for the embedded and control efficiency $90 \%$ for the wet floor and ceiling systems and $91.3 \%$ for the dry floor system. The dynamic simulations provide for the wet floor and the ceiling as average $96 \%$ in non-insulated buildings, in insulated buildings and in masonry well-insulated buildings, $98 \%$ in well-insulated buildings with light structures. The dry floor presents an embedded and control efficiency of about $93 \%$ in non-insulated buildings and in insulated buildings, $95 \%$ in masonry well-insulated buildings, and $98 \%$ in well-insulated buildings with light structures.

Referring to the new version of the standard 15316-2-2017 [38], the current values of the temperature difference $\Delta T_{i, e m b}+\Delta T_{i, c t r}$ are higher than the ones calculated in the present work. Based in the dynamic simulations, the suggested values for the joint embedded and control temperature differences are the ones reported in Table 8, which should substitute the existing default values. Moreover, the efficiency calculated in transient conditions is higher than the efficiency calculated under steady state conditions. This result is because, over the season, the radiant systems work for some hours and then they switch off. Part of the thermal energy embedded in the structures is not lost when the water stops flowing in the pipes, but it is later released to the room.

When considering the overall energy consumed by a water to water heat pump (including the auxiliaries) the increased amount of hours of pumping in the case of variable temperature is counterbalanced by the higher COP of the heat pump, which increases when the supply temperature decreases; overall the climatic control leads to $5-6 \%$ better performance in floor heating systems and $7-8 \%$ better performance with radiant ceilings. Overall the radiant ceiling consumes always more 
than the two floor systems due to the higher supply temperature (about $11 \%$ in the case of variable temperature and $15 \%$ in case of fixed temperature). Of course, the higher the insulation the higher the performance, hence, the light structures perform better than the masonry structures due to the lower U-values.

Looking at long-term comfort evaluations results, no particular problem has been found in the period from December to February according to EN 15251 category II. The analysis carried out was mainly related to check the overtemperature, i.e., when the temperature is above the set-point temperature plus the dead band fixed in $0.5{ }^{\circ} \mathrm{C}$ in the present work. The results show that overtemperature rises when the insulation increases. In masonry structures radiant ceiling has always the highest values of $\mathrm{WF}^{+}$, especially in case of constant supply temperature. This is due to the higher water temperature supply, although the radiant structure is light. In well-insulated light structures the dry floor shows the highest overtemperature. Anyway, it has to also be underlined that in the ideal convective system simulations the overtemperature is comparable with the ones of the radiant systems simulations. In particular when dividing $\mathrm{WF}^{+}$by the number of hours when the overtemperature occurs $\mathrm{h}^{+}$, the intensity of overtemperature $\left(\mathrm{WF}^{+} / \mathrm{h}^{+}\right)$shows that the results of radiant systems and ideal convective case are of the same magnitude. This means that, with radiant systems the amount of hours when the overtemperature occurs, $\mathrm{h}^{+}$is higher, but the intensity of the overtemperature is similar than in the ideal convective case.

Resuming the results, the work carried out shows that in general the better the quality of the envelope the better the overall performance of the radiant system. Evaluating the efficiency in dynamic conditions leads to higher efficiencies compared to steady state conditions, former standard EN 15316-2-2007 and also the new standard EN15316-2-2017 and new suggested values are provided. Working at variable temperature leads to lower consumptions compared to fixed supply temperature over the season. No problems of comfort have been found in the period from December to February. Overtemperature effects are not especially due to radiant system, but they also happen in any case with ideal convective systems. As with all emission systems, the radiant systems may lead to higher overtemperature effects, but the effect is evident in terms of higher amount of hours when the overtemperature happens rather than too high temperatures because of the radiant system operation.

In general, the radiant ceilings perform worse than radiant floor systems in heating conditions and there is no evidence that dry floor systems perform better than wet screed systems in all the types of buildings regardless of the level of insulation and thermal inertia.

As a final remark, it has to be underlined that it would be interesting to analyse the same building in cooling conditions, where the radiant ceiling could work better than the radiant floor system. Moreover, the work which has been carried out here considers a unique room; a further interesting study would be to analyse different rooms, i.e., looking in detail at the distribution of the inner space and checking the different possible control strategies.

Author Contributions: Simulations and data analysis, G.A.; Methodology and Project Administration, M.D.C.; Software and Validation, A.Z.; Conceptualization, Writing-Review \& Editing, A.D.B.

Funding: This research received no external funding.

Acknowledgments: This research was supported by Q-RAD, Italian Association of Radiant Systems Producers.

Conflicts of Interest: The authors declare no conflict of interest. 


\section{Nomenclature}

\begin{tabular}{|c|c|c|}
\hline$\Delta T_{i, e m b}$ & Temperature difference for the embedded losses & {$[\mathrm{K}]$} \\
\hline$\Delta T_{i, c t r}$ & Temperature difference for the control losses & {$[\mathrm{K}]$} \\
\hline$\eta_{e m b}$ & Embedded efficiency of the system & {$[-]$} \\
\hline$\eta_{c t r l}$ & Control efficiency of the system & {$[-]$} \\
\hline$\phi_{u}$ & Specific useful thermal power of a radiant system & {$\left[\mathrm{W} \mathrm{m} \mathrm{m}^{-2}\right]$} \\
\hline$\phi_{l}$ & Specific thermal losses of a radiant system & {$\left[\mathrm{W} \mathrm{m}^{-2}\right]$} \\
\hline$c_{p}, c_{v}$ & Specific heat of the air & {$[\mathrm{J} /(\mathrm{kg} \mathrm{K})]$} \\
\hline$c_{w}$ & Specific heat of the water & {$[\mathrm{J} /(\mathrm{kg} \mathrm{K})]$} \\
\hline C & Radiant ceiling with plasterboard coupled with insulation panels & {$[-]$} \\
\hline COP & Coefficient of Performance & {$[-]$} \\
\hline $\mathrm{COP}_{\text {id }}$ & Coefficient of Performance in ideal conditions (for a Carnot cycle) & {$[-]$} \\
\hline$C O P_{i d, \text { nom }}$ & Coefficient of Performance of a Carnot cycle in nominal conditions & {$[-]$} \\
\hline$C O P_{\text {nom }}$ & Coefficient of Performance in nominal conditions & {$[-]$} \\
\hline$E_{h p}$ & Energy consumption of the heat pump & {$[-]$} \\
\hline$F_{j-k}$ & View factor between surface $\mathrm{j}$ and $\mathrm{k}$ & {$[-]$} \\
\hline FD & Radiant floor with wet screed & {$[-]$} \\
\hline FW & Radiant floor with dry screed and aluminum plate diffuser & {$[-]$} \\
\hline$h_{c, j}$ & Convective heat exchange coefficient & {$\left[\mathrm{W} /\left(\mathrm{m}^{2} \mathrm{~K}\right)\right]$} \\
\hline$h_{c, w}$ & Convective heat exchange coefficient of the water inside the pipe & {$\left[\mathrm{W} /\left(\mathrm{m}^{2} \mathrm{~K}\right)\right]$} \\
\hline$h_{o p}$ & Operation time of the radiant system & {$[\mathrm{h}]$} \\
\hline $\mathrm{h}^{+}$ & Time when overtemperature & {$[\mathrm{h}]$} \\
\hline$h_{r, j}$ & Radiative heat exchange coefficient & {$\left[\mathrm{W} /\left(\mathrm{m}^{2} \mathrm{~K}\right)\right]$} \\
\hline$\dot{m}_{b}$ & Mass flow rate of the incoming air & {$[\mathrm{kg} / \mathrm{s}]$} \\
\hline$\dot{m}_{w}$ & Mass flow rate of the water & {$[\mathrm{kg} / \mathrm{s}]$} \\
\hline$M_{a}$ & Mass of the air & {$[\mathrm{kg}]$} \\
\hline$M_{w}$ & Mass of the water & {$[\mathrm{kg}]$} \\
\hline$q_{c, j}$ & Convective heat flux for the $j$-th general surface element & {$[\mathrm{W}]$} \\
\hline$q_{r, j}$ & Radiative heat flux for the $j$-th general surface element & {$[W]$} \\
\hline$Q_{i d}$ & $\begin{array}{l}\text { Thermal energy, calculated through ideal convective simulation, } \\
\text { needed to keep the room at the desired air temperature }\end{array}$ & {$[\mathrm{kWh}]$} \\
\hline$Q_{w}$ & $\begin{array}{l}\text { Thermal energy calculated from the temperature difference of supply } \\
\text { and return water of the radiant system }\end{array}$ & {$[\mathrm{kWh}]$} \\
\hline$S_{j}$ & Surface of the generic element & {$\left[\mathrm{m}^{2}\right]$} \\
\hline$T_{a}$ & Indoor air temperature of the room & {$[\mathrm{K}]$} \\
\hline$T_{b}$ & Temperature of the incoming air & {$[\mathrm{K}]$} \\
\hline$T_{\text {cond }}$ & Reference condensing temperature & {$[\mathrm{K}]$} \\
\hline$T_{\text {evap }}$ & Reference evaporating temperature & {$[\mathrm{K}]$} \\
\hline$T_{f, j}$ & $\begin{array}{l}\text { Temperature of the fluid: either internal air, or air of the adjacent room } \\
\text { or sol-air for surfaces facing outdoor }\end{array}$ & {$[\mathrm{K}]$} \\
\hline$T_{o}$ & Operative temperature & {$\left[{ }^{\circ} \mathrm{C}\right]$} \\
\hline$T_{o, u l}$ & Upper limit of the range of acceptability for operative temperature & {$\left[{ }^{\circ} \mathrm{C}\right]$} \\
\hline$T_{s, j}$ & Surface temperature of the generic element & {$[\mathrm{K}]$} \\
\hline$T_{s, p}$ & Surface temperature of the pipe element & {$[\mathrm{K}]$} \\
\hline$T_{w, i n}$ & Supply water temperature & {$\left[{ }^{\circ} \mathrm{C}\right]$} \\
\hline$T_{w, \text { in }, \text { cond }}$ & Inlet temperature of the water in the condenser & {$[\mathrm{K}]$} \\
\hline$T_{w, i n, e v a p}$ & Inlet temperature of the water in the evaporator & {$[\mathrm{K}]$} \\
\hline$T_{w, \text { out }, \text { cond }}$ & Outlet temperature of the water in the condenser & {$[\mathrm{K}]$} \\
\hline$T_{w, \text { out }, \text { evap }}$ & Outlet temperature of the water in the evaporator & {$[\mathrm{K}]$} \\
\hline $\mathrm{WF}^{+}$ & Weighted factor related to overtemperature & {$\left[{ }^{\circ} \mathrm{C}\right]$} \\
\hline $\mathrm{WF}^{+} / \mathrm{h}^{+}$ & Overtemperature intensity & {$\left[{ }^{\circ} \mathrm{C} / \mathrm{h}\right]$} \\
\hline
\end{tabular}




\section{Appendix A}

Table A1. Stratigraphy and thermal properties of the structures of the not insulated building (N).

\begin{tabular}{|c|c|c|c|c|c|c|c|}
\hline & \multirow{2}{*}{ Layer } & s & $\lambda$ & $\rho$ & c & $\mathbf{R}$ & $\mathbf{U}$ \\
\hline & & [m] & 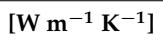 & {$\left[\mathrm{kg} \mathrm{m}^{-3}\right]$} & {$\left[\mathrm{J} \mathrm{kg}^{-1} \mathrm{~K}^{-1}\right]$} & {$\left[\mathrm{m}^{2} \mathrm{~K} \mathrm{~W}^{-1}\right]$} & 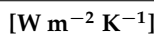 \\
\hline \multirow{6}{*}{ External wall } & Liminar inner layer & - & - & - & - & 0.125 & \multirow{6}{*}{1.333} \\
\hline & Plaster & 0.015 & 0.900 & 1800 & 1000 & 0.017 & \\
\hline & Hollow brick & 0.120 & 0.660 & 1100 & 840 & 0.182 & \\
\hline & Hollow brick & 0.250 & 0.676 & 1516 & 840 & 0.370 & \\
\hline & Plaster & 0.015 & 0.900 & 1800 & 1000 & 0.017 & \\
\hline & Liminar outer layer & - & - & - & - & 0.040 & \\
\hline \multirow{5}{*}{ Internal wall } & Liminar inner layer & - & - & - & - & 0.125 & \multirow{5}{*}{2.069} \\
\hline & Plaster & 0.015 & 0.900 & 1800 & 1000 & 0.017 & \\
\hline & Hollow brick & 0.080 & 0.400 & 775 & 840 & 0.200 & \\
\hline & Plaster & 0.015 & 0.900 & 1800 & 1000 & 0.017 & \\
\hline & Liminar outer layer & - & - & - & - & 0.125 & \\
\hline \multirow{7}{*}{ Floor } & Liminar inner layer & - & - & - & - & 0.125 & \multirow{7}{*}{1.444} \\
\hline & Ceramic tiles & 0.010 & 1.000 & 2300 & 840 & 0.010 & \\
\hline & Screed & 0.060 & 0.700 & 1600 & 880 & 0.086 & \\
\hline & Concrete & 0.040 & 1.480 & 2200 & 1000 & 0.027 & \\
\hline & Structural Slab & 0.200 & 0.660 & 1100 & 840 & 0.303 & \\
\hline & Plaster & 0.015 & 0.900 & 1800 & 1000 & 0.017 & \\
\hline & Liminar outer layer & - & - & - & - & 0.125 & \\
\hline
\end{tabular}

Table A2. Stratigraphy and thermal properties of the structures of the insulated buildings (IM, IE, and II).

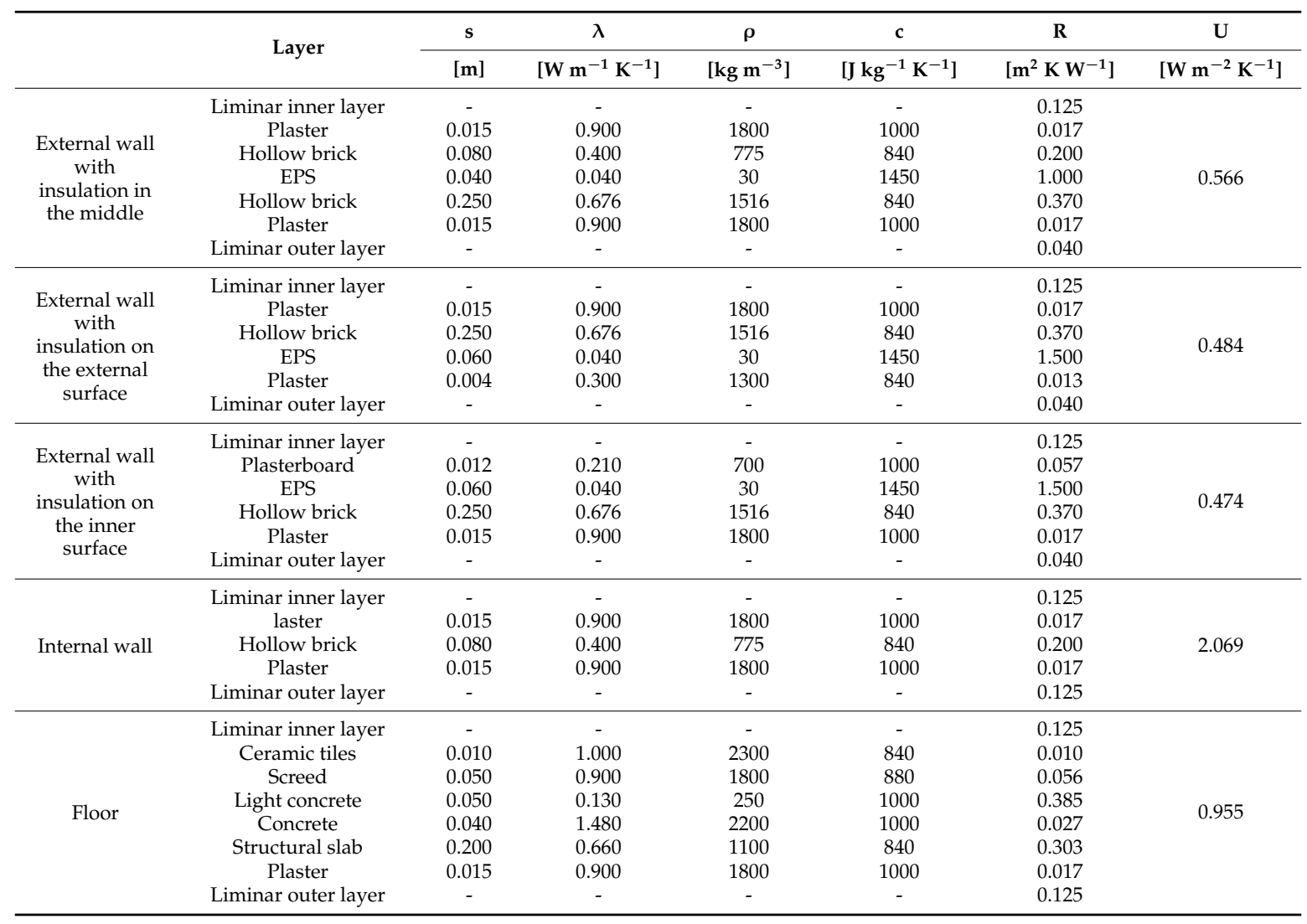


Table A3. Stratigraphy and thermal properties of the structures of the well-insulated masonry buildings (WIE and WII).

\begin{tabular}{|c|c|c|c|c|c|c|c|}
\hline & \multirow{2}{*}{ Layer } & $\mathbf{s}$ & $\lambda$ & $\rho$ & c & $\mathbf{R}$ & $\mathbf{U}$ \\
\hline & & {$[\mathrm{m}]$} & {$\left[\mathrm{W} \mathrm{m}^{-1} \mathrm{~K}^{-1}\right]$} & {$\left[\mathrm{kg} \mathrm{m}^{-3}\right]$} & {$\left[\mathrm{J} \mathrm{kg}^{-1} \mathrm{~K}^{-1}\right]$} & {$\left[\mathrm{m}^{2} \mathrm{KW}^{-1}\right]$} & 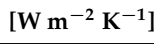 \\
\hline \multirow{4}{*}{$\begin{array}{l}\text { External wall } \\
\text { with } \\
\text { insulation on } \\
\text { the external } \\
\text { surface }\end{array}$} & Liminar inner layer & - & - & - & - & 0.125 & \multirow{4}{*}{0.215} \\
\hline & Light bricks & 0.250 & 0.430 & 870 & 1000 & 0.581 & \\
\hline & EPS with graphite & 0.120 & 0.031 & 20 & 1450 & 3.871 & \\
\hline & Plaster & 0.004 & 0.300 & 1300 & 840 & 0.013 & \\
\hline \multirow{5}{*}{$\begin{array}{l}\text { External wall } \\
\text { with } \\
\text { insulation on } \\
\text { the inner } \\
\text { surface }\end{array}$} & Plasterboard & 0.012 & 0.210 & 700 & 1000 & 0.057 & \multirow{5}{*}{0.224} \\
\hline & EPS with graphite & 0.120 & 0.031 & 20 & 1450 & 3.871 & \\
\hline & Bricks & 0.280 & 0.778 & 1800 & 840 & 0.360 & \\
\hline & Plaster & 0.015 & 0.900 & 1800 & 1000 & 0.017 & \\
\hline & Liminar outer layer & - & - & - & - & 0.040 & \\
\hline Internal wall & Liminar inner layer & - & - & - & - & 0.125 & 2.069 \\
\hline \multirow{8}{*}{ Floor } & Liminar inner layer & - & - & - & - & 0.125 & \multirow{8}{*}{0.719} \\
\hline & Ceramic tiles & 0.010 & 1.000 & 2300 & 840 & 0.010 & \\
\hline & Screed & 0.030 & 0.900 & 1800 & 880 & 0.033 & \\
\hline & EPS & 0.030 & 0.040 & 30 & 1450 & 0.750 & \\
\hline & Concrete & 0.040 & 1.480 & 2200 & 1000 & 0.027 & \\
\hline & Structural slab & 0.200 & 0.660 & 1100 & 840 & 0.303 & \\
\hline & Plaster & 0.015 & 0.900 & 1800 & 1000 & 0.017 & \\
\hline & Liminar outer layer & - & - & - & - & 0.125 & \\
\hline
\end{tabular}

Table A4. Stratigraphy and thermal properties of the structures of the well-insulated, lightweight buildings (WIX and WIL).

\begin{tabular}{|c|c|c|c|c|c|c|c|}
\hline & $\mathbf{I}$ & $\mathbf{s}$ & $\lambda$ & $\rho$ & c & $\mathbf{R}$ & $\mathbf{U}$ \\
\hline & Layer & [m] & 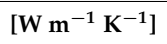 & {$\left[\mathrm{kg} \mathrm{m}^{-3}\right]$} & {$\left[\mathrm{J} \mathrm{kg}^{-1} \mathrm{~K}^{-1}\right]$} & {$\left[\mathrm{m}^{2} \mathrm{KW}^{-1}\right]$} & 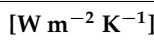 \\
\hline \multirow{7}{*}{$\begin{array}{c}\text { Wood } \\
\text { external wall }\end{array}$} & Liminar inner layer & - & - & - & - & 0.125 & \multirow{7}{*}{0.150} \\
\hline & Plasterboard & 0.0125 & 0.210 & 700 & 1000 & 0.060 & \\
\hline & Wood fiber & 0.100 & 0.039 & 150 & 2100 & 2.564 & \\
\hline & Cross laminated timber & 0.100 & 0.130 & 500 & 1600 & 0.769 & \\
\hline & Wood fiber & 0.120 & 0.039 & 150 & 2100 & 3.077 & \\
\hline & Plaster & 0.015 & 0.900 & 1800 & 1000 & 0.017 & \\
\hline & Liminar outer layer & - & - & - & - & 0.040 & \\
\hline \multirow{5}{*}{$\begin{array}{l}\text { Light external } \\
\text { wall }\end{array}$} & Liminar inner layer & - & - & - & - & 0.125 & \multirow{5}{*}{0.190} \\
\hline & Plasterboard & 0.015 & 0.210 & 700 & 1000 & 0.071 & \\
\hline & EPS & 0.200 & 0.040 & 30 & 1450 & 5.000 & \\
\hline & Plaster & 0.015 & 0.900 & 1800 & 1000 & 0.017 & \\
\hline & Liminar outer layer & - & - & - & - & 0.040 & \\
\hline \multirow{5}{*}{ Internal wall } & Liminar inner layer & - & - & - & - & 0.125 & \multirow{5}{*}{0.377} \\
\hline & Plasterboard & 0.0125 & 0.210 & 700 & 1000 & 0.060 & \\
\hline & Mineral wool & 0.080 & 0.035 & 40 & 1030 & 2.286 & \\
\hline & Plasterboard & 0.0125 & 0.210 & 700 & 1000 & 0.060 & \\
\hline & Liminar outer layer & - & - & - & - & 0.125 & \\
\hline \multirow{10}{*}{ Floor } & Liminar inner layer & - & - & - & - & 0.125 & \multirow{10}{*}{0.199} \\
\hline & Ceramic tiles & 0.010 & 1.000 & 2300 & 840 & 0.010 & \\
\hline & Concrete & 0.060 & 1.000 & 1800 & 880 & 0.060 & \\
\hline & EPS & 0.030 & 0.039 & 30 & 1250 & 0.769 & \\
\hline & Wood fiber & 0.040 & 0.039 & 150 & 2100 & 1.026 & \\
\hline & Light concrete & 0.100 & 0.130 & 250 & 1000 & 0.769 & \\
\hline & Cross laminated timber & 0.160 & 0.130 & 500 & 1600 & 1.231 & \\
\hline & Mineral fiber & 0.030 & 0.035 & 40 & 1030 & 0.857 & \\
\hline & Plasterboard & 0.0125 & 0.210 & 700 & 1000 & 0.060 & \\
\hline & Liminar outer layer & - & - & - & - & 0.125 & \\
\hline
\end{tabular}


Table A5. Stratigraphy and thermal properties of the radiant floor with wet screed (FW).

\begin{tabular}{|c|c|c|c|c|c|c|}
\hline \multirow{2}{*}{ Layer } & $\mathrm{s}$ & $\lambda$ & $\rho$ & c & $\mathbf{R}$ & $\mathrm{U}$ \\
\hline & {$[\mathrm{m}]$} & {$\left[\mathrm{W} \mathrm{m}^{-1} \mathrm{~K}^{-1}\right]$} & {$\left[\mathrm{kg} \mathrm{m}^{-3}\right]$} & {$\left[\mathrm{J} \mathrm{kg}^{-1} \mathrm{~K}^{-1}\right]$} & {$\left[\mathrm{m}^{2} \mathrm{~K} \mathrm{~W}^{-1}\right]$} & {$\left[\mathrm{W} \mathrm{m} \mathrm{m}^{-2} \mathrm{~K}^{-1}\right]$} \\
\hline Ceramic tiles & 0.010 & 1.000 & 2300 & 840 & 0.010 & \multirow{4}{*}{1.10} \\
\hline Screed & 0.060 & 1.000 & 1800 & 880 & 0.060 & \\
\hline $\begin{array}{l}\text { Pipes } 17 \times 2 \mathrm{~mm} \text {, } \\
15 \mathrm{~cm} \text { pitch }\end{array}$ & - & 0.360 & 951 & 2300 & - & \\
\hline Insulation & 0.025 & 0.033 & 30 & 1250 & 0.750 & \\
\hline
\end{tabular}

Table A6. Stratigraphy and thermal properties of the radiant floor with dry screed and aluminum diffusers (FD).

\begin{tabular}{|c|c|c|c|c|c|c|}
\hline \multirow{2}{*}{ Layer } & $\mathbf{s}$ & $\lambda$ & $\rho$ & c & $\mathbf{R}$ & $\mathrm{U}$ \\
\hline & [m] & {$\left[\mathrm{W} \mathrm{m}^{-1} \mathrm{~K}^{-1}\right]$} & {$\left[\mathrm{kg} \mathrm{m}^{-3}\right]$} & {$\left[\mathrm{J} \mathrm{kg}{ }^{-1} \mathrm{~K}^{-1}\right]$} & {$\left[\mathrm{m}^{2} \mathrm{~K} \mathrm{~W}^{-1}\right]$} & {$\left[\mathrm{W} \mathbf{m}^{-2} \mathrm{~K}^{-1}\right]$} \\
\hline Ceramic tiles & 0.010 & 1.000 & 2300 & 840 & 0.010 & \multirow{5}{*}{1.10} \\
\hline Dry screed & 0.009 & 0.170 & 950 & 1030 & 0.053 & \\
\hline $\begin{array}{l}\text { Pipes } 14 \times 2 \mathrm{~mm} \text {, } \\
10 \mathrm{~cm} \text { pitch }\end{array}$ & - & 0.360 & 951 & 2300 & - & \\
\hline Conducting device & 0.001 & 237 & 2710 & 896.9 & $4.2 \cdot 10^{-6}$ & \\
\hline Insulation & 0.025 & 0.033 & 30 & 1250 & 0.750 & \\
\hline
\end{tabular}

Table A7. Stratigraphy and thermal properties of the radiant ceiling with plasterboard coupled to insulation panels (C).

\begin{tabular}{|c|c|c|c|c|c|c|}
\hline \multirow{2}{*}{ Layer } & $\mathbf{s}$ & $\bar{\lambda}$ & $\bar{\rho}$ & c & $\mathbf{R}$ & $\mathrm{U}$ \\
\hline & {$[\mathrm{m}]$} & {$\left[\mathrm{W} \mathrm{m}^{-1} \mathrm{~K}^{-1}\right]$} & {$\left[\mathrm{kg} \mathrm{m}^{-3}\right]$} & {$\left[\mathrm{J} \mathrm{kg}^{-1} \mathrm{~K}^{-1}\right]$} & {$\left[\mathrm{m}^{2} \mathrm{~K} \mathrm{~W}^{-1}\right]$} & {$\left[\mathrm{W} \mathrm{m}^{-2} \mathrm{~K}^{-1}\right]$} \\
\hline Plasterboard & 0.0125 & 0.210 & 700 & 1000 & 0.060 & \multirow{3}{*}{0.89} \\
\hline $\begin{array}{l}\text { Pipes } 10 \times 1 \mathrm{~mm} \text {, } \\
6 \mathrm{~cm} \text { pitch }\end{array}$ & - & 0.360 & 951 & 2300 & - & \\
\hline Insulation & 0.030 & 0.033 & 35 & 1450 & 0.91 & \\
\hline
\end{tabular}

\section{References}

1. Shoemaker, R.W. Le chauffage par rayonnement; Editions Eyrolles: Paris, France, 1954. (In French)

2. Olesen, B.W. Possibilities and limitations of radiant floor cooling. ASHRAE Trans. 1997, 103, 42-48.

3. ISO 11855. Building Environment Design-Design, Dimensioning, Installation and Control of Embedded Radiant Heating and Cooling Systems; ISO: Geneva, Switzerland, 2012.

4. Bojic, M.; Loveday, D.L. The influence on building thermal behavior of the insulation/masonry distribution in a three-layered construction. Energy Build. 1997, 26, 153-157. [CrossRef]

5. Gagliano, A.; Patania, F.; Nocera, F.; Signorello, C. Assessment of the dynamic thermal performance of massive buildings. Energy Build. 2014, 72, 361-370. [CrossRef]

6. Balaras, C.A. The role of thermal mass on the cooling load of buildings. An overview of computational methods. Energy Build. 1996, 24, 1-10. [CrossRef]

7. Aste, N.; Angelotti, A.; Buzzetti, M. The influence of the external walls thermal inertia on the energy performance of well insulated buildings. Energy Build. 2009, 41, 1181-1187. [CrossRef]

8. Stazia, F.; Bonfiglia, C.; Tomassonia, E.; Di Perna, C.; Munafò, P. The effect of high thermal insulation on high thermal mass:Is the dynamic behaviour of traditional envelopes in Mediterranean climates still possible? Energy Build. 2015, 88, 367-383. [CrossRef]

9. Aste, N.; Leonforte, F.; Manfren, M.; Mazzon, M. Thermal inertia and energy efficiency-Parametric simulation assessment on a calibrated case study. Appl. Energy 2015, 145, 111-123. [CrossRef]

10. Verbekea, S.; Audenaerta, A. Thermal inertia in buildings: A review of impacts across climate and building use. Renew. Sustain. Energy Rev. 2018, 82, 2300-2318. [CrossRef]

11. ASHRAE Handbook-HVAC Systems and Equipment; ASHRAE: Atlanta, GA, USA, 2012.

12. Babiak, J.; Olesen, B.W.; Petras, D. REHVA Guidebook No 7: Low Temperature Heating and High. Temperature Cooling; REHVA: Brussels, Belgium, 2009. 
13. Koschenz, M.; Dorer, V. Interaction of an air system with concrete core conditioning. Energy Build. 1999, 30, 139-145. [CrossRef]

14. Sattari, S.; Farhanieh, B. A parametric study on radiant floor heating system performance. Renew. Energy 2006, 31, 1617-1626. [CrossRef]

15. Seo, J.; Jeon, J.; Lee, J.H.; Kim, S. Thermal performance analysis according to wood flooring structure for energy conservation in radiant floor heating systems. Energy Build. 2011, 43, 2039-2042. [CrossRef]

16. Seo, J.; Park, Y.; Kim, J.; Kim, S.; Kim, S.; Kim, J.T. Comparison of thermal transfer characteristics of wood flooring according to the installation method. Energy Build. 2014, 70, 422-426. [CrossRef]

17. Wu, X.; Zhao, J.; Olesen, B.W.; Fang, L.; Wang, F. A new simplified model to calculate surface temperature and heat transfer of radiant floor heating and cooling systems. Energy Build. 2015, 105, 285-293. [CrossRef]

18. Zhang, D.; Cai, N.; Wang, Z. Experimental and numerical analysis of lightweight radiant floor heating system. Energy Build. 2013, 61, 260-266. [CrossRef]

19. Zhao, K.; Liu, X.-H.; Jiang, Y. Dynamic performance of water-based radiant floors during start-up and high-intensity solar radiation. Sol. Energy 2014, 101, 232-244. [CrossRef]

20. Qiu, L.; Li, Q. Analyses on two paving types of floor heating. In Proceedings of the 2011 International Conference on Computer Distributed Control and Intelligent Environmental Monitoring, Changsha, China, 19-20 February 2011.

21. Thomas, S.; Franck, P.Y.; Andre, P. Model validation of a dynamic embedded water base surface heat emitting system for buildings. Build. Simul. 2011, 4, 41-48. [CrossRef]

22. Weber, T.; Jóhannesson, G.; Koschenz, M.; Lehmann, B.; Baumgartner, T. Validation of a FEM-program (frequency-domain) and a simplified RC-model (time-domain) for thermally activated building component systems (TABS) using measurement data. Energy Build. 2005, 37, 707-724. [CrossRef]

23. De Carli, M.; Scarpa, M.; Tomasi, R.; Zarrella, A. DIGITHON: A numerical model for the thermal balance of rooms equipped with radiant systems. Build. Environ. 2012, 57, 126-144. [CrossRef]

24. Stephenson, D.G.; Mitalas, G.P. Cooling load calculation by thermal response factor method. ASHRAE Trans. 1967, 73, 1-7.

25. Kusuda, T. Thermal response factors for multi-layer structures of various heat conduction systems. ASHRAE J. 1969, 11, 64.

26. Blomberg, T. Heat2-A PC-Program for Heat Transfer in Two Dimensions. Manual with Brief Theory and Examples; Lund Group for Computational Building Physics: Lund, Sweden, 1999.

27. De Carli, M.; Tonon, M. Effect of modelling solar radiation on the cooling performance of radiant floors. Sol. Energy 2011, 85, 689-712. [CrossRef]

28. Berglund, L.G.; Gagge, A.P. Human response to thermal conditions maintained in an office by radiant ceiling, baseboard, forced air and floor heating systems. ASHRAE Trans. 1985, 91, 488-502.

29. Külpmann, R.W. Thermal comfort and air quality in rooms with cooled ceilings-Results of scientific investigations. ASHRAE Trans. 1993, 99, 488-502.

30. Fisher, D.R.; Pedersen, C.O. Convective heat transfer in building energy and load calculation. ASHRAE Trans. 1997, 103, 137-148.

31. De Carli, M.; Tomasi, R. A critical review on heat exchange coefficients between heated and cooled horizontal surfaces and room. In Proceedings of the 11th Roomvent 2009 Conference, Busan, Korea, 24-27 May 2009.

32. Athienitis, A.K.; Chen, Y. The effect of solar radiation on dynamic thermal performance of floor heating systems. Sol. Energy 2000, 69, 229-237. [CrossRef]

33. Schlunder, E.U.; Zhukauskas, A.A. Fluid Mechanics and Heat Transfer. In Heat Exchanger Design Handbook; Begell House Publishers: New York, NY, USA, 1983.

34. EN 12831-1. Energy Performance of Buildings. Method for Calculation of the Design Heat Load-Part. 1: Space Heating Load; CEN: Brussels, Belgium, 2017.

35. Mazzarella, L.; Dati climatici, G. De Giorgio. In Proceedings of the Giornata di studio Giovanni De Giorgio, Milano, Italy, 18 November 1997.

36. ISO 13786. Thermal Performance of Building Components_Dynamic Thermal Characteristics_Calculation Methods; ISO: Geneva, Switzerland, 2017.

37. EN 15316. Heating Systems in Buildings-Method for Calculation of System Energy Requirements and System Efficiencies-Part. 2-1: Space Heating Emission Systems; CEN: Brussels, Belgium, 2007. 
38. EN 15316. Energy Performance of Buildings-Method for Calculation of System Energy Requirements and System Efficiencies; CEN: Brussels, Belgium, 2017.

39. EN 15251. Indoor Environmental Input Parameters for Design and Assessment of Energy Performance of Buildings-Addressing Indoor Air Quality, Thermal Environment, Lighting and Acoustics; CEN: Brussels, Belgium, 2007.

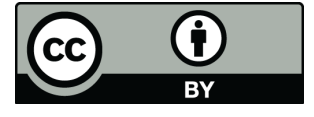

(c) 2018 by the authors. Licensee MDPI, Basel, Switzerland. This article is an open access article distributed under the terms and conditions of the Creative Commons Attribution (CC BY) license (http://creativecommons.org/licenses/by/4.0/). 